STONE CENTER ON SOCIO-ECONOMIC INEQUALITY

WORKING PAPER SERIES

No. 11

The Decline in Intergenerational Mobility After 1980

Jonathan M.V. Davis

Bhashkar Mazumder

February 2020

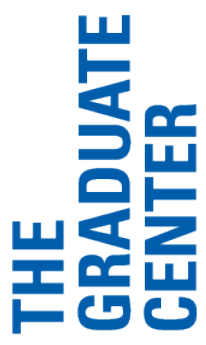

CITY UNIVERSITY

OF NEW YORK 


\title{
The Decline in Intergenerational Mobility After 1980*
}

\author{
Jonathan M.V. Davis \\ Department of Economics, University of Oregon \\ 516 PLC, 1285 University of Oregon, Eugene, OR 97403 \\ jdavis5@uoregon.edu \\ Bhashkar Mazumder \\ Federal Reserve Bank of Chicago and University of Bergen \\ 230 S LaSalle St, Chicago, IL 60604 \\ bhash.mazumder@gmail.com
}

February 21, 2020

\begin{abstract}
We demonstrate that relative intergenerational mobility declined sharply for cohorts born in the early 1960s compared to those born around 1950. The former entered the labor market largely after the large rise in inequality that occurred around 1980 while the latter entered the labor market well before this inflection point. We show that the rank-rank slope rose from 0.24 to 0.36 and the IGE increased from 0.21 to 0.50 . We find that both the increase in the returns to schooling and the gradient in the likelihood of marriage by parent income can explain some of the increase in persistence. We also find direct evidence of a decline in absolute intergenerational mobility using intergenerational data, consistent with the bounds-based approach of Chetty et al. (2017).
\end{abstract}

*Avinash Moorthy and Karl Schulze provided excellent research assistance. We thank participants at the 2017 AEA meetings, the 2019 Statistics Norway workshop on intergenerational mobility, gender and family formation in the long-run, and the University of Oregon. We also thank Ilyana Kuziemko and Nathan Deutscher for helpful comments. Any errors are our own. The views expressed here do not necessarily represent the views of the Federal Reserve Bank of Chicago or the Federal Reserve System 


\section{Introduction}

One of the most notable changes in the U.S. economy in recent decades has been the rise in inequality. A key inflection point appears to be around 1980. During the early 1980s there was a pronounced increase in the 90-10 income gap and a sharp rise in the income share of the top 1 percent (see Figure 1). At the same time, consumption inequality (Meyer and Sullivan, 2013), the returns to education (Goldin and Katz, 1999), and income segregation (Reardon et al., 2018) all grew markedly. With the advent of a more unequal society, concerns about a possible decline in equality of opportunity have risen to the forefront of policy discussion in the U.S.

To better understand equality of opportunity, researchers have increasingly focused attention on studies of relative intergenerational mobility. These studies estimate the association between parent income and the income of their offspring as adults. If the strength of the association is high, it suggests that there may be a low degree of intergenerational mobility as a family's position in the income distribution is largely replicated from one generation to the next. In contrast, if associations are relatively small, then we might infer that there is a high degree of mobility as families are more likely to move up and down the income distribution. The consensus view is that intergenerational income mobility in the U.S. is low compared to other advanced economies (e.g. Black and Devereux, 2007, Bratberg et al., 2017). Further, high inequality countries tend to have lower rates of intergenerational mobility -a pattern that has been referred to as the "Great Gatsby curve" (e.g. Corak, 2013).

Has it always been the case that intergenerational mobility has been low in the U.S.? Between 1948 and 1973, for example, the U.S. economy experienced a long period of relatively rapid economic growth and much lower inequality than in the period since. One might wonder whether intergenerational income mobility might have been much more rapid for individuals who entered the labor market during this so-called "golden age." 1 Interestingly, there is very little evidence on this point. Aaronson and Mazumder (2008) do find evidence of greater mobility in the decades prior to 1980. However, Aaronson and Mazumder (2008) do not use intergenerationally linked samples and instead rely on a more indirect "synthetic cohort"

\footnotetext{
${ }^{1}$ Studies of earlier historical periods (Long and Ferrie, 2013 Olivetti and Paserman, 2015) suggest that intergenerational mobility fell early in the 20th century but those studies do not examine trends in more recent decades.
} 
approach that links groups of parents and children across Decennial Censuses by state and year of birth of the child. A potential problem with this approach, relative to the traditionally estimated intergenerational elasticity, is that their estimator places greater weight on the geographic effects of state of birth. Hilger (2017) also uses historical Census data and finds evidence of more rapid mobility prior to 1980 but confines his analysis to mobility with respect to education, not income. Finally, Chetty et al. (2017) study cohorts born as far back as 1940 but only with respect to absolute mobility and they do not observe directly linked parent-child income before 1980. They find evidence of a large decline in absolute mobility over this period. We also estimate a decline in absolute mobility as we discuss later.

We believe that we are the first study to fully utilize the longitudinal income data reported by both parents and children in the National Longitudinal Surveys (NLS) to directly measure changes in intergenerational mobility for large samples of relevant cohorts.2 We document that intergenerational mobility was substantially lower for cohorts born in the early 1960s who entered the labor market after the rise in inequality compared to those born roughly a decade earlier around 1950, who would have entered the labor market around 1970 and would have been much less affected by the major inflection point in the economy around 1980.

The NLS are uniquely suited to address this question because they utilize cohortbased sampling frames providing large samples with significant overlap with the ideal "pre" and "post" cohorts 3 In contrast, several previous studies on trends in intergenerational mobility have relied on the Panel Study of Income Dynamics (PSID) While the PSID is a highly valuable resource for intergenerational analysis, it has limitations that make it less suitable for studying longer-term trends (Mazumder. 2018). We discuss these limitations in great detail in Section 6. In particular it has inadequate coverage of the "pre-cohorts" and the sample sizes per birth cohort are

${ }^{2}$ Levine and Mazumder (2002) and Bloome and Western (2011) have also used the NLS but do not use the self-reported family income in the NLS66's "Older Men" and "Mature Women" samples and instead use a categorical family income measure in the young men's survey (which could also reflect some of the child's own earnings). Because they only use the NLS66's young men's sample (discussed in more detail in the next section), they only measure children's income until they are in their late 20s and early 30s. Levine and Mazumder (2007) only look at changes in the brother correlation in income. In particular, they do not look at changes in the association between parent and child income measures. In an earlier working paper draft circulating in 2017, we also did not utilize links to parents through the "Mature Women" sample.

${ }^{3}$ We describe the ideal cohorts for this analysis in more precise detail in Section 2.1

${ }^{4}$ See Hertz (2007), Lee and Solon (2009), Hartley et al. (2017), Justman and Krush (2013), Justman et al. (2017), and Justman and Stiassnie (2020). 
too small to estimate the cross-cohort changes we focus on in this analysis.

The NLS are also superior to currently available administrative records for studying trends in intergenerational mobility. For example, the population-wide tax records used by Chetty et al. (2014b) only cover 17 years (1996 to 2012) and cannot be used to estimate time trends covering cohorts born in the 1940s 5 Therefore, in order to establish the basic facts on changes in intergenerational mobility for these cohorts, researchers must either use the best available survey data or utilize indirect approaches. The NLS are the best suited survey data since they contain large samples of the cohorts needed for studying trends around the rise in inequality. Nevertheless, given that many newer studies on intergenerational mobility in the U.S. utilize administrative data (e.g. Mazumder, 2005, Chetty et al., 2014b) we provide an extensive set of robustness checks to ensure readers that the NLS surveys are reliable and that the cross-cohort changes that we document are not driven by changes in survey design, response rates, attrition, missing values or any other artifacts of the data.

We measure intergenerational mobility using both the rank-rank slope and the intergenerational elasticity (IGE). The rank-rank slope describes the rate of intergenerational persistence in ranks providing a measure of positional mobility. The IGE provides a measure of intergenerational income persistence and can be used to infer how long gaps in log income across families are likely to persist. The IGE is also inclusive of changes in inequality over generations. In both cases, a higher value indicates greater persistence and less mobility.

We show that by both measures persistence increased markedly between these two cohort groups. The rank-rank slope rose from 0.24 to 0.36 while the IGE rose from 0.21 to 0.50 . To put these findings in context, the temporal variation in US rank mobility is of a similar magnitude to the geographic variation in rank mobility documented by Chetty et al. (2014b) for the 1980-82 cohorts. The cross-cohort decline in mobility is the equivalent of moving from the 6th percentile city (MSA) to the 60 th percentile city

We document two notable cross cohort changes that could explain the increase in intergenerational income persistence 7 These include the increase in the returns

\footnotetext{
${ }^{5}$ We also show that our findings are consistent with Chetty et al. (2014a) who use tax records to estimate very short time trends in income rank mobility from 2001 to 2012 covering cohorts born between 1971 and 1982. We also discuss other potential administrative data sources in Section 2.1.

${ }^{6}$ See Chetty et al. (2014b)'s online table 4 that presents estimates for 381 MSAs.

${ }^{7}$ We only explore whether concurrent changes in the economy can explain the observed decline
} 
to post-secondary education and the increase in the gradient between parent income and whether a child ever became married. We find that both of these changes can account for some of the increase in persistence.

Finally, we use our sample to document changes in one particular measure of absolute intergenerational mobility - the share of children with a higher income than their parents (Isaacs et al. , 2008). In a highly cited study, Chetty et al. (2017) use an indirect bounds-based approach in order to measure long-term trends in this statistic. Their main estimates suggest that absolute mobility declined from around 90 percent for cohorts born around 1940 to 50 percent for cohorts born around 1980 . We are able to use direct intergenerational linkages and find a more modest decline in absolute mobility among our cohort groups for which income was measured at similar ages for parents and children, going from 63 percent for the cohorts born around 1950 to 51 percent for the cohorts born in the early 1960s. Our estimates, however, are well within the bounds estimated by Chetty et al. (2017) and are consistent with their general finding of a decline absolute mobility 8 Therefore, we conclude that intergenerational mobility has declined in both absolute and relative terms in the US.

\section{Data}

We use the National Longitudinal Surveys of Older Men and Young Men and Mature Women and Young Women (NLS66) and the National Longitudinal Survey of Youth 1979 (NLSY79). We construct our samples to maximize comparability across these surveys.

\subsection{Ideal Cohorts for Analysis}

We begin by explaining why we think the National Longitudinal Surveys (NLS) are the best available data for our analysis. We would like to examine a group of cohorts that entered the labor market around 1980 and experienced the sharp

in intergenerational mobility across cohorts. Nybom and Stuhler (2016) show that changes in intergenerational mobility may not even necessarily reflect contemporaneous events and in principle, could be due to changes in policy or the economic environment that occurred well in the past.

${ }^{8}$ In an earlier version of this working paper circulating in 2017 we found a much smaller decline in absolute mobility. We believe that this was likely due to the fact that we were not utilizing children in the NLS66 who were matched to parents through the Mature Women sample. In that earlier analysis we were therefore relying on samples with older and more socioeconomically advantaged parents. 
increase in inequality during their formative years in the labor market. We would ideally compare them to a cohort group who entered the labor market ten years earlier and would not have been "treated" by the rise in inequality during these formative years. Topel and Ward (1992) document that the majority of wage growth occurs during the first ten years on the job so cohorts who roughly entered the labor market around 1970 can be thought of as much less affected by the surge in inequality.

If we assume that most individuals enter the labor market between the ages of 18 and 22, then this would suggest that those who entered the labor market in 1980 would have been born between 1958 and 1962. If we also included those born in the subsequent five years (1963-1967) then a reasonable classification of the cohorts exposed to the rise in inequality ("post-cohorts") would be those born between 1958 and 1967. In fact, the NLSY79 was explicitly designed to be representative of the national population of those born between 1957 and 1964 thereby providing substantial overlap with this group.

The "pre-cohort" group would include 18 to 22 year olds who entered the labor market exactly ten years earlier in 1970 who would have been born between 1948 and 1952. If we also included those born in the preceding five years (1943 to 1947) then a reasonable comparison group of earlier cohorts would be those born between 1943 and 1952. The NLS66 includes cohorts born between 1942 and 1953, which substantially overlaps with this group.

In contrast, no other datasets provide this kind of overlap with both cohort groups. With respect to administrative data, the 1984 SIPP matched to SSA earnings records used by Mazumder (2005) and Dahl and DeLeire (2008) covers cohorts born as early as the mid-1960s who entered the labor market well after 1980. The IRS data used by Chetty et al. (2014b) includes cohorts born from 1980 to 1982 . Chetty et al. (2014a) use a small sample of birth cohorts born as far back as 1971 . Mitnik et al. (2015) use another IRS data source, the "SOI-M" panel which represents children born between 1972 and 1975 who also would have entered the labor market well after 1980. The PSID has minimal coverage of the pre-cohorts as most studies only use cohorts born since 1952. Furthermore, the sample size per cohort is too small to lead to precise estimates of cross-cohort changes. We discuss these issues in great detail in Section 6 . 


\subsection{National Longitudinal Surveys of Older Men and Young Men and Mature Women and Young Women (NLS66)}

The NLS66 separately sampled young men who were 14-24 years old on March 31 , 1966, young women who were 14-24 on December 31, 1967, older men who were 45-59 on March 31, 1966, and older women who were 30-44 as of March 31, 1967. As part of the initial sampling design the different surveys frequently include respondents from common households. This allows us to link a subset of the cohort of young men/young women to their parents if at least one of their parents was also included in one of the two older cohort samples. Once we can link a child to one of the parents, we can then typically obtain information about the other parent as well through the survey questions about the other household members. To avoid over-representing children who live with their parents in adulthood, we restrict our sample to parent-child households where the child was 18 or younger in the first survey year 9 With these restrictions, our NLS66 analysis sample consists of 2,465 parent-child pairs including 1,253 parent-son pairs and 1,212 parent-daughter pairs. Daughters were born between 1949 and 1953 and sons were born between 1948 and 1952. Table 1 presents summary statistics 10

The Mature Women's survey sampled women who were 30-44 years old in 1967. Combined with the Young Men/Young Women age restrictions, this implies that in principle, mother-son links include mothers who were between 10 and 30 years old at the time of their son's birth and mother-daughter links include mothers who were between 11 and 31 years old at the time of their daughter's birth. The Older Men's survey sampled much older individuals (45-59 in 1966), so linked fathers were between 26 and 46 (27 and 47) years old when their son (daughter) was born. Consequently, most children are linked to their parents through the link to the mother in the Mature Women's sample. Among the 2,465 parent-child pairs, 75 percent of children were linked to their parents through a mother in the Mature Women Survey while only 35 percent of children were linked to their parents through a father in the Older Men Survey 110 percent were linked to parents through both surveys. A diagram showing how the children were linked to one or both parents is

\footnotetext{
${ }^{9}$ We show that our finding of a statistically significant increase in intergenerational persistence is robust to changing this sample restriction in Appendix Figure A1.

${ }^{10} \mathrm{We}$ discuss the missingness of income and possible biases in subsection 5.2

${ }^{11}$ An earlier working paper draft only linked children to parents through the Older Men's cohort leading us to over-represent children with older parents. Since we have now added links to the Mature Women's cohort, our sample is much larger and much more representative.
} 
shown in Figure 2. In section 5.1 we show that this set of parent age restrictions has no effect on our findings. ${ }^{12}$

In each of the four surveys we observe the total family income of the entire household 13 Therefore total family income will include both parents' income whenever both parents are present (and report their income) irrespective of how the parent link was made. We measure real total family income in the parent generation in 2015 dollars using the average of all available total family income reports in the first three survey waves where income data was collected 14 Table 1, Panel B shows that total family income in the parent generation was $\$ 73,274$ on average. Fathers were present for 94 percent of children and were 45.5 years old on average across the years income is measured. Mothers were present for 99.5 percent of children and were aged 42.2 on average. Children were on average 16.8 years old across these years.

Unlike the Young Women's survey which continued through 2003, the Young Men's survey was discontinued more than 20 years earlier in 1981. Therefore, for the NLS66, we only observe sons relatively early in their career at an average age of around 29.15 In contrast, daughters are followed into the prime of their careers at an average age of around 41. We measure daughters' adult family income using the average of all available total family income from 1991, 1993, and 1995 from the Young Women surveys when the daughters were 41 years old and their spouses were 43, on average. We measure sons' adult family income using all available total family income reports from the 1978, 1980, and 1981 Young Men surveys when sons were 29 years old and their spouses were 28, on average. Spouses were present for just under 75 percent of both sons and daughters. Across all parent-child pairs, total family income in the child generation is $\$ 79,474$ on average.

We weight our analysis using the child's survey weight in the first round of the survey ${ }^{16}$ We show that our results are not sensitive to our choice of weights,

\footnotetext{
${ }^{12}$ We estimate that only about 5 percent of families are likely missed, that this rate of missing families was constant over time and that imposing this age restriction appears to have no effect on estimates in the NLSY79 where we can estimate our results both with and without this restriction.

${ }^{13}$ We construct our total family income measure by adding up all income reports from the respondent and, when present, from their spouse and any other household members. See appendix section A for more details.

${ }^{14}$ Income is converted to real terms using the CPI-U.

${ }^{15}$ Appendix Table A1 shows summary statistics separately for parent-daughter and parent-child pairs.

${ }^{16}$ These weights are necessary to make the survey samples representative of the national samples they target because both surveys used stratified sampling designs with heterogeneous probabilities
} 
including not using any weight, in subsection 5.4 .

\subsection{National Longitudinal Survey of Youth 1979 (NLSY79)}

The NLSY79 was designed as a replication of the NLS66 Young Men and Young Women's cohorts (Center for Human Resource Research, 2001). The sample was designed to be representative of the 1979 population living in the U.S. born between 1957 and 1964. We combine a nationally representative sample of 6,111 individuals and an oversample of 5,295 Hispanic, Black, and economically disadvantaged nonBlack, non-Hispanic individuals.

We construct our NLSY79 sample to mirror the NLS66 samples as closely as possible. We mimic the restriction in the NLS66 that children must be matched to a father in the Older Men survey or a mother in the Mature Women's survey by requiring that children have either a father or mother in the age ranges implied by the NLS66's sample frames 17 To be included in our sample, daughters in the NLSY79 either had to have a father who was between 27 and 47 years old at the time of their birth, mimicking the NLS66 daughter to father linkage, or a mother who was between 11 and 31 at the time of their birth, mirroring the NLS66 daughter to mother linkages. Likewise, we require sons be matched to fathers who were between 26 and 46 or to mothers who were between 10 and 30 at the time of their birth 18 Table 1 shows that only 6 percent of the (weighted) sample in the NLSY79, or 369 parent-child pairs, are dropped because of this restriction.19

We restrict our sample to parent-child households where the child was 18 or younger in the first survey year. Consequently, our NLSY79 samples include children from the 1961 to 1964 cohorts.

Parents were asked to report total family income from the previous year in 1979, 1980, and 1981 when their children were still living at home. Our parent income measure averages all non-missing family income for up to three years. Table 1

of being sampled (Solon et al., 2015). Using weights is especially important given our use of the rank-rank slope with ranks defined by parents' and children's rank in their respective marginal income distributions.

${ }^{17}$ Appendix Table A2 shows that our NLSY79 results are not sensitive to imposing this restriction.

${ }^{18}$ Overall, 55 percent of children in the NLSY79 are linked to a father, 82 percent of children are linked to a mother, and 37 percent of children are linked to both parents.

${ }^{19}$ Figure A5 shows 95 percent of children had a parent meeting these criteria in each decennial census between 1940 and 1970. Importantly, since this restriction binds at a similar rate over time, it does not contribute to trends in intergenerational mobility. And as mentioned above, Appendix Table A2 shows that our NLSY79 results are not sensitive to imposing this restriction. 
shows average family income in the parent generation is $\$ 78,599$ in 2015 dollars. On average, fathers were present for 88 percent of children and were 45.3 years old, on average, when income is measured. Mothers were present for 99 percent of children and were 41.8 years old on average in these years. Children were 16.3 years old, on average, when income is measured.

In order to mimic the data restriction in our NLS66 sample we measure adult income at different points in the life-cycle for parent-daughter and parent-son samples ${ }^{20}$ For the parent-daughter sample, we use the average of all non-missing measures of total family income in the previous year from the 2002, 2004, and 2006 surveys when the women were on average 40.5 years old and their spouses were aged 43.0. For the parent-son sample, we use the average of all non-missing measures of total family income from the 1991, 1992, and 1994 surveys when the men were 28.8 years old and their spouses were 27.8 years old, on average. Spouses were present for 61 percent of women and 51 percent of men. Across all parent-child pairs, the average total family income in the child generation is $\$ 76,283.21$

As with the NLS66, we weight our analysis using the child's survey weight in the first round of the survey.

\section{Methods}

Our estimates of intergenerational mobility in the NLS66 and NLSY79 are based on the following regression:

$$
M_{1 i s}=\alpha+\beta I_{i s}+\gamma^{N L S 66} M_{0 i}\left(1-I_{i s}\right)+\gamma^{N L S Y 79} M_{0 i} I_{i s}+\delta W \text { omen }_{i}+\varepsilon_{i s},
$$

where $i$ indexes parent-child pairs and $s$ denotes pair $i$ 's survey (NLS66 or NLSY79). $M_{0}$ and $M_{1}$ represent income measures where 0 indexes the parent generation and 1 indexes the child generation. $I_{i s}$ is an indicator for whether parent-child pair $i$ is in the NLSY79 sample. $\gamma^{N L S 66}$ and $\gamma^{N L S Y 79}$ are intergenerational mobility measures

\footnotetext{
${ }^{20}$ We also show estimates for the NLSY79 where we use the same age ranges for both sons and daughters. This is shown in Appendix Table A2

${ }^{21}$ The standard deviation of family income in the child generation is larger for the NLSY79 than the NLS66 because the income distribution has a longer right tail. If we drop the 21 families with incomes between $\$ 386,929$, the maximum value in the NLS66, and $\$ 1,235.852$, the maximum value in the NLSY79, the standard deviation is $\$ 55,608$. We show in subsection 5.3 that are results are not sensitive to how we treat these outliers.
} 
for the NLS66 and NLSY79, respectively ${ }^{22}$ For our pooled estimates that include both parent-son and parent-daughter pairs, we also include an indicator variable for being a parent-daughter pair. $\varepsilon_{i s}$ is the component of the child's income measure that is unexplained by the other covariates. We allow for heteroskedastic errors across children and for the errors of children living in the same household to be correlated.

We use two types of income measures, ranks and log income. For ranks, we calculate the percentile in each generation's total family income distribution separetly for parent-daughter and parent-son pairs. Here, the coefficients $\gamma^{N L S 66}$ and $\gamma^{N L S Y 79}$ are interpretable as rank-rank slopes for the NLS66 and NLSY79 cohorts, respectively. Note that "rank-rank slope" is just another name for the Spearman correlation coefficient. Second, we use log total family income in each generation. In this case, $\gamma^{N L S 66}$ and $\gamma^{N L S Y 79}$ represent the intergenerational elasticity (IGE) for each cohort. When using log income, the small number of parent-child pairs with negative total family income are dropped from the analysis.

Appendix Figure A4 shows binned scatter plots for both of our income measures. The figures demonstrate that the relationships are all approximately linear, justifying our linear specifications.

\section{Results}

Table 2, Column 1 shows estimates of $\gamma^{N L S 66}$ and $\gamma^{N L S Y 79}$ for all parent-child pairs using the rank-rank specification. Among all parent-child pairs with children born between 1948 and 1953 ("earlier cohorts"), the rank-rank slope is 0.24 . In contrast, the rank-rank slope among parent-child pairs with children born between 1961 and 1964 ("later cohorts") is 0.36 , implying a 50 percent increase. The difference between rank persistence across these two cohort groups is 0.12 which is highly statistically significant $(\mathrm{p}<0.01) 23$ The standard error on this difference is 0.03 and the 95

\footnotetext{
${ }^{22}$ While we do not include controls for parent age at birth or children's birth year in our main specification, we show in Appendix Figure A2 that our results are highly robust to their inclusion.

${ }^{23}$ Appendix Figure A2 shows that our estimates of the decline in intergenerational mobility are robust to the inclusion of birth year fixed effects or birth year fixed effects and a quartic polynomial in parent age at birth. Appendix Figure A1 also shows our results are robust to changing our sample restriction that children be 18 or younger at their first interview. We estimate similar declines if we restrict our sample to children who were $16,17,18,19,20,21,22$, or any age at their first interview. One might also worry that we are measuring parent income in fixed calendar years rather than at a particular parent age. Appendix Figure A3 shows the estimates are generally quite similar to the full sample results even across subsamples of children whose parent generation income was
} 
percent confidence interval is 0.07 to 0.18 .

To benchmark the magnitude of this increase, we compare these rank-rank slopes to estimates by city (MSA) reported in Chetty et al. (2014b). The rank persistence for the earlier cohorts, 0.24 , corresponds to the 22nd most mobile city out of the 381 cities in Chetty et al. s (2014b) data. For the later cohorts, born just over a decade later, rank persistence corresponds to the 227th most mobile city. Being born around in the early 1960s instead of around 1950 is similar to moving from an MSA at the 6th percentile of the intergenerational persistence distribution to a city at the 60 th percentile of this distribution.

Column 2 shows estimates for all parent-child pairs using the IGE specification. In this case, the increase in persistence is even more stark. Among the earlier cohorts (with positive income), the IGE is 0.21 . But among the later cohorts, the IGE is 0.50 . This 0.29 unit difference is again highly statistically significant $(\mathrm{p}<0.01)$. The standard error on the difference is 0.04 and the 95 percent confidence interval around this difference ranges from 0.22 to 0.37 .

The plausibility of such an increase across cohort groups is further supported by Figure 3 where we show estimates of the rank-rank slope (left panel) and the IGE (right panel) separately for individuals in each birth year covered by our data. We find that there were large year to year increases within the earlier cohort group (1948 to 1953). Specifically, the rank-rank slope increased by about 0.02 per year and the IGE increased by about 0.03 units per year. If persistence continued to increase at the same rates for cohorts born up to 1961, this would yield estimates that would be reasonably consistent with what we actually find for the later cohorts. We also show that intergenerational persistence appears to have stabilized and perhaps declined among the later cohorts. In section 6, we show that our estimates for the rank-rank slope and the IGE for the later cohorts are well in line with the previous literature. Prior studies have not shown direct estimates for our full set of earlier cohorts 24

In both the NLS66 and NLSY79, daughters are followed through their, and when married, their husband's prime earning years ${ }^{25}$ In contrast, the NLS66's young men

measured when their father was anywhere from 40 to 49 years old in the year of the first parent generation income report.

${ }^{24}$ Aaronson and Mazumder (2008), using an indirect method, show estimates for 5-year cohort bins that are highly consistent with the cross-cohort changes we find. They find a large increase in persistence for cohorts born between 1946-50 and 1961-65 which is shown in their figure 3B.

${ }^{25}$ Appendix Table A2 shows NLSY79 estimates for the pooled sample and separately for sons and daughters when using early career income and prime income, with and without the restriction that parents be in the age ranges that would have put them in the NLS66 sample frame. 
cohort was only followed until 1981 before reaching their peak earning years. We construct NLSY79 parent-son pairs to mirror this restriction. Due to lifecycle bias (Haider and Solon, 2006), IGE estimates and to a lesser extent, rank-rank slopes, are typically lower when children are measured early in their career rather than during the prime of their life cycle (Nybom and Stuhler, 2017; Mazumder, 2016). Therefore, we expect to find lower estimates among the parent-son pairs than the pooled sample of all parent-child pairs.

Because of these concerns due to life cycle issues, the next two pairs of columns show estimates separately for parent-daughter and parent-son pairs. We reiterate that we are using total family income which includes spouse's income when a spouse is present, for both parent-daughter and parent-son pairs. Among the parentdaughter pairs, the rank-rank slope increased from 0.27 for the earlier cohorts to 0.35 for the later cohorts. This 27 percent increase is statistically significant at the 10 percent level $(\mathrm{p}=0.06)$. The IGE increased 91 percent, rising from 0.28 for the earlier cohorts to 0.53 for the later cohorts. This increase is highly statistically significant $(\mathrm{p}<0.01)$.

As predicted, using early career income instead of prime age income for the parent-son pairs yields attenuated IGE and, to a lesser extent, rank-rank, estimates. The 1948 to 1952 cohorts' parent-son rank-rank and IGE estimates are 26 and 50 percent smaller than the comparable estimates using parent-daughter pairs, respectively ${ }^{26}$ The 1961 to 1964 parent-son IGE estimate is 10 percent smaller than the comparable estimate using parent-daughter pairs, but the rank-rank estimate is actually 9 percent larger. Despite these differences, our main result that persistence is significantly higher for the later cohorts than for the earlier cohorts is unchanged. The rank-rank slope nearly doubled, increasing from 0.20 to 0.38. The IGE more than tripled, going from 0.14 to 0.48 . These estimates are significantly different from each other at conventional levels $(\mathrm{p}<0.01)$.

\section{Differences in Data Quality}

The literature on intergenerational economic mobility has often been concerned about measurement issues in order to produce accurate estimates of persistence at a

\footnotetext{
${ }^{26}$ Recall that because of the different timing of the NLS66 surveys for young men and young women and our restriction to only those children 18 and younger, our sample of daughters covers the 1949 to 1953 cohorts while our sample of sons includes the 1948 to 1952 cohorts.
} 
point in time. These issues include the length of the time average of parent income used and the age at which parent and child income is measured (e.g. Solon, 1992, Mazumder, 2005, Haider and Solon, 2006, Nybom and Stuhler, 2017). Therefore, we have been very careful to address these first order measurement concerns that have dominated the literature by ensuring that the length of time averages and that the average ages of parents and children are virtually identical across our two cohort groups. As a result, these biases are unlikely to affect our inferences regarding changes over time. Nevertheless, there still may be concerns about whether there are other aspects of the data that could lead to spurious findings.

In this section, we explore whether differences in data quality between the NLS66 and NLSY79 can provide a plausible alternative explanation for our results. To address this, we first compare the survey's sampling procedures and response rates and show that these cannot account for our findings. Indeed the two surveys were designed to be quite similar. Next, we compare rates of missingness and zero income reports across the two surveys and show are results are robust to restricting our sample to observations with positive income reports in each survey year included in our analysis. Third, we show our results are robust to dropping or topcoding observations with very high incomes. Fourth, we show our results are robust to our choice of survey weights. Finally, we compare the income distributions in each survey to analogous income distributions constructed using the Current Population Survey's Annual Social and Economic Supplement data under the assumption that the CPS data is representative. While we find some differences between the NLS and CPS distributions, the differences are similar for the NLS66 and NLSY79 and we show that reweighting our samples to mimic the income distributions in the CPS has no effect on our conclusions.

\subsection{Sampling and Response Rates}

Section 2 discusses how we construct our NLSY79 sample to mimic the NLS66's more complex sampling design. In this subsection, we provide additional details about each surveys sampling procedures and response rates. With our adjustment to the NLSY79 sample to match the NLS66, the samples are comparable on all of these dimensions, as was intended when the NLSY79 was commissioned.

The process for selecting individuals designated to participate in the NLS66 surveys and the NLSY79 was intentionally similar because the NLSY79 was designed as a replication of the NLS66 Young Men and Young Women cohorts (Center for 
Human Resource Research, 2001) ${ }^{27}$ In both cases, samples were selected through a multi-stage process. First, a set of geographic sample areas is randomly selected. All households in these sample areas are screened to determine if the house is occupied by individuals in the survey's sample frame. The set of individuals designated to be in the survey is then selected by randomly sampling households with individuals in the survey's sample frame using a stratified random sample with higher selection probabilities for minority populations. Both surveys frequently include multiple respondents from the same household.

The rates at which individuals designated for the survey completed their first interview were quite high and similar across all of the surveys. For the NLS66, the first survey response rates were 91.5 percent for sons, 93.2 percent for daughters, 91.0 percent for fathers, and 94.3 percent for mothers. For the NLSY79, the response rate of youth was 90 percent. For the NLSY79, parents' information was collected using a household questionnaire during the youth's interview. Table 3 shows that parent income information was collected for 92.3 percent of children in the NLSY79. Because parent income is observed for virtually every parent-child pair in the NLS66 (99.5 percent), the rate at which children designated for the survey make it in to our sample is comparable across both surveys.

As discussed in Section 2, the key difference between the NLS66 and the NLSY79 is that the child and at least one parent needed to be in a sample frame to be included in the NLS66 whereas only the child needed to be in the NLSY79 sample frame. Consequently, NLS66 mother-son links include mothers who were between 10 and 30 years old at the time of their son's birth and mother-daughter links include mothers who were between 11 and 31 years old at the time of their daughter's birth. Similarly, NLS66 father-son links include fathers who were between 26 and 46 years old when their son was born and father-daughter links include fathers who were between 27 and 47 years old when their daughter was born. This sampling is summarized in Figure 2. In contrast, the NLSY79 sample frame does not impose restrictions on parents' age when their child was born.

To make the samples comparable, we require that children in the NLSY79 have either a father or mother in the age ranges implied by the NLS66's sample frames. Among the full NLSY79 sample, 94 percent of children have a parent in the age range imposed by the NLS66 sample frame. As a result, only 6 percent of observations

\footnotetext{
${ }^{27}$ See https://www.nlsinfo.org/content/cohorts/ for details on the selection of respondents and response rates.
} 
are dropped from the NLSY79 sample when we impose this restriction. Appendix Table A2 shows that our rank-rank slope and IGE estimates for the 1961 to 1964 cohorts typically only change by 1 or 2 percent if this restriction is not imposed 28

While we cannot directly report the share of children excluded from the NLS66 because of the parent age restriction because they are never in the sample, Figure A5 shows that the restriction binds at a virtually identical rate for cohorts born around 1950 and 1960. In particular, 95 percent of children had a parent meeting these criteria in each decennial census between 1940 and 1970.

The bottom line is that the NLSY79 and NLS66's sampling and response rates are very similar, but the NLS66 sample frame misses certain types of parent-child pairs relative to the NLSY79 (e.g. children with single moms who were in their late 30 s at the time of their birth or children whose mother was in her 30s and whose father was in his 20 s at the time of their birth). We drop these types of parent-child pairs from the NLSY79 to make the samples comparable. Only about five percent of parent-child pairs are in this group, and this rate has been stable over time, so this restriction is extremely unlikely to have any impact on our estimates.

\subsection{Sensitivity to Missing Income}

In samples with missing data, there is a well-known tradeoff between maintaining representativeness by including as many observations as possible and minimizing missingness, by dropping observations with any missing data. In our main analysis, we try to maximize the representativeness of our sample by including any parentchild pairs for which we observe at least one non-zero family income measure for both generations. We then average across all available family income observations in each generation. Table 3, Panel A shows that this requirement is satisfied by 73 percent of parent-child pairs in the NLS66 and 79 percent of parent-child pairs in the NLSY79. At least one non-zero parent income report is observed for basically all children in the NLS66 and for 92 percent of children in the NLSY79. At least one non-zero child income measure is observed for 73 and 85 percent of NLS66 and NLSY79 children, respectively.

\footnotetext{
${ }^{28}$ The IGE for the 5 percent of NLS66 parent-child pairs dropped because of this restriction would need to be implausibly large to explain the 0.29 unit difference between the two cohorts. Assuming the residual variance is comparable in the observed and unobserved parent-child pairs, the IGE would need to be about 6.0 in the missing parent-child pairs to explain the difference. While this is an implausible level of persistence in its own right, it is especially unlikely given that including these observations has little effect on the IGE estimate for the NLSY79 cohorts.
} 
Table 3. Panel B shows details of each annual income measure included in our parent income measure, conditional on having at least one non-zero income measure. On average, 2.89 and 2.31 non-zero annual income reports are observed for parents of children in the NLS66 and NLSY79. Parent income is rarely missing in the NLS66. In the NLSY79, the first parent income report is missing for 12.4 percent of children and this missingness increases to 34.6 percent for the third income report.

Analogous details are shown for our child income reports in Table 3 , Panel C. The patterns of missingness in the child income reports are quite similar across the two surveys. On average we observe 2.7 and 2.8 non-zero annual income reports for children in the NLS66 and NLSY79, respectively. In the NLS66, 4.7, 8.8, and 14.1 percent of children are missing the first, second, and third income reports. In the NLSY79, 5.0, 5.3, and 7 percent of children are missing these same income reports.

One might worry that differential missingness across surveys could be driving some of the differences in intergenerational mobility between the two cohorts. To be sure, if the higher rates of missingness among the NLSY79's parent generation family income measures induce greater measurement error in our parent generation family income measure, this would attenuate the difference between the NLSY79 and the NLS66 and make us underestimate an increase in intergenerational persistence. However, if measurement error in the child generation is differentially correlated with parent income between the two cohorts, this could potentially explain some of the increase in persistence in our main sample.

To address this concern, Table 4 replicates our main analysis with only parentchild pairs for which every parent and child income report is non-missing and nonzero. Making this restriction shows us how our estimates change as we allow for less missing data. This should be informative more generally, about how the degree of missingness affects our estimates. Columns 1 and 2 show estimates exactly replicating our main results using this subsample. Columns 3 and 4 show analogous estimates adjusted for selection into the subsample with inverse probability weights (IPW). These are just the usual sample weights divided by the probability an observation is included in the sample, calculated separately by parent income decile for parent-daughter and parent-son pairs in each survey.

In this subsample with all non-missing, non-zero income reports, we find that the rank-rank slope increased from 0.20 to 0.33 across cohorts without the IPW adjustment or from 0.22 to 0.36 with the adjustment. We find that the IGE more than doubled, going from 0.19 to about 0.42 with or without the IPW correction. 
These results suggest that differential missingness is not driving our results. The decline in the rank-rank slope is nearly identical to the decline using all of the available data and the decline in the IGE is only slightly smaller than the analogous estimate using all of the available data. When observations with missing or zero income reports are excluded, we estimate a slightly lower, but broadly similar, level of persistence. The rank-rank slope is about 0.2 for cohorts born around 1950 and is a little over 0.3 for cohorts born just after 1960 . For cohorts born around 1950, the IGE is also about 0.2 whether or not observations with missing data are excluded. For cohorts born just after 1960, the IGE is about 0.5 when observations with missing data are included, and is about 0.4 when they are excluded.

\subsection{Sensitivity to Extreme Values}

One might also worry that changes in how very large incomes are treated could be driving the observed changes in persistence. Table 5 explores the robustness of our results to different adjustments for extreme values. Column 1 drops a parent-child pair if the parent was in the top 5\% of their generation's income distribution. Rather than dropping these parent-child pairs, Column 2 topcodes parent income with the average income of parents in the top $5 \%$ of the income distribution separately by survey and whether the pair is a parent-daughter or parent-child pair. Columns 3 and 4 make analogous adjustments but for both parent and child income instead of just parent income.

Panels A and B show the results from these exercises for the rank-rank slope and IGE, respectively. In all cases, we find a large and statistically significant increase in persistence. The increase in the rank-rank slope narrowly ranges from 0.11 to 0.12 across these exercises, compared to 0.12 in our main analysis. The increase in the IGE ranges from 0.28 to 0.30 , compared to 0.29 in our main analysis.

\subsection{Attrition and Sensitivity to Different Weights}

Schoeni and Wiemers (2015) show that using sample weights corrects for some of the bias in intergenerational elasticity estimates due to attrition. Our main analysis uses individuals' survey weight from their first-round interview, which primarily corrects for differences in the probability of being included in the sample. Table 6 shows our main results are robust to our choice of survey weights. Each column shows the results using a different set of weights. Since ranks are based on the 
weighted distribution, we generate a new set of parent and child generation ranks using each set of weights. The first column shows the unweighted results. The second column shows results using the weights from the first interview round, which are the weights we use in our main specification. The third and fourth columns show the results using the first or last non-missing weights during the survey rounds where we measure child income. Lastly, the fifth column shows the results using the average weight across all survey rounds where we measure child income. Panel A shows the rank-rank estimates for all parent-child pairs. Panel B shows the IGE estimates for all parent-child pairs.

While the increase in persistence is significant across all specifications, it is smallest when no weights are used. In this case, the estimates suggest the rank-rank slope increased from 0.30 to 0.40 , or by 36 percent, and the IGE increased from 0.24 to 0.52, or by 119 percent. Both the rank-rank slope and IGE estimates are similar regardless of whether we use the weights from the first interview round, the first round included in our child income measure, the last round included in our child income measure, or the average weight across all survey rounds included in the child income measure. In each of those cases, the rank-rank slope increases from 0.24 or 0.25 to between 0.36 and 0.38 . The IGE increases from 0.21 to 0.50 or 0.51 , except when the average weight is used in which case it increases to 0.47 .

\subsection{Comparisons of income distributions with the CPS}

As a final check on the relative data quality of each survey, we compare the parent and child generation income distributions to analogous distributions created using the income data reported in the Current Population Survey's (CPS) Annual Social and Economic Supplement (ASEC) in Figure 4. For the CPS parent income distributions, we limit the sample to families with a child in the household born in the appropriate birth cohort using the calendar years included in our parent generation income measures. We use one observation per family with the weight scaled by the number of children in the family. We only use the cross-sectional variation in the CPS. To make the NLS data more comparable to the CPS, we reshape our NLS data to "long-form" with one observation per individual-calendar year.

A major limitation of this effort is that the ASEC supplement did not start until 1970 so there is only one year of overlap, 1970, between the years used for the NLS66 parent income distribution (1968, 1969 and 1970) and the ASEC data. Based on this imperfect comparison, both the NLS66 and NLSY79's parent income 
distributions appear to underrepresent low income families and overrepresent middle and upper-middle income families.

For the child income distributions, we limit the sample to respondents in the appropriate birth cohorts in calendar years included in our child generation income measures. In this case, we are able to include income from the same calendar years for both the NLS and CPS distributions. Like the parent income distributions, both the NLS66 and NLSY79 parent income distributions underrepresent individuals in low and middle income families and overrepresent individuals from upper middle income families compared to the analogous income distributions constructed from CPS ASEC data.

While the NLS distributions do not exactly match the CPS distributions, there do not appear to be meaningful differences between how well the NLS66 and NLSY79 distributions match the CPS data that would systematically affect our findings of changes over time. Nevertheless, we find that if we reweight our samples to mimic the CPS distributions, we find very similar results. The reweighted distributions are shown in Appendix Figures A6 to A8 and the reweighted estimates are shown in Appendix Table A3.

\section{Reconciling Our Estimates with the Prior Literature}

Our study is the first to fully utilize the longitudinal parent and child income data available in the NLS surveys in order to document trends in intergenerational mobility. Our earlier cohorts, born between 1948 and 1953 entered the labor market during the 1960s and 1970s, well before the increase in inequality and the returns to schooling that took place around 1980. Our later cohorts, born between 1961 and 1964 in contrast, largely entered the labor market after the pronounced rise in inequality. We find a large and economically significant increase in intergenerational persistence between these groups. The rank-rank slope increased by 50 percent and the IGE more than doubled.

It is worth noting that Bloome and Western (2011) also document a significant increase in the IGE across these same cohort groups. However, they used a categorical family income measure included in the Young Men's survey rather than the self-reported income of parents. Similarly, Levine and Mazumder (2007) show that the sibling correlation in log wages, log annual earnings and log family income rose by a similar amount between the NLS66 and NLSY79. The sibling correlation 
is a broader measure of family background that encompasses other shared factors besides parent income.

The prior literature has estimated intergenerational persistence for our later cohorts using a variety of data and approaches. Our estimates are generally quite similar to previous studies. For the rank-rank slope, our estimate for the more recent cohorts using the NLSY79 (1961 to 1964) is 0.36 with a standard error of 0.02 and 95 percent confidence interval from 0.33 to 0.40 . Our point estimate is very similar to estimates of 0.34 obtained by Chetty et al. (2014b) using modern cohorts (1980-82), estimates of around 0.3 obtained by Dahl and DeLeire (2008) using Social Security earnings files on cohorts born between 1963 and 1972, estimates of around 0.3 to 0.4 obtained by Mazumder (2016) using the PSID and an estimate of 0.39 by Bratberg et al. (2017), who also use the NLSY and include the 1957 to 1964 cohorts. Our rank-rank slopes are only different compared to the earlier literature precisely when we consider cohorts born between 1948 and 1953 -which has not been done directly in the previous literature. This is one of the main contributions of our paper.

With respect to the intergenerational elasticity in family income for the more recent cohorts (1961 to 1964), our main estimate is 0.5 with a standard error of 0.03 and a 95 percent confidence interval from 0.45 to 0.55 . This is in line with the received literature that has used a variety of data sources. For example, Solon]s (1992) estimate using the PSID is 0.483, Hertz s (2007) estimate using PSID is 0.538 , Jäntti et al.'s (2006) estimate of the elasticity of family income on children's earnings using the NLSY79 is 0.517. Mitnik et al.'s (2015) estimates using IRS SOI-M panel data are between 0.55 and 0.74. Chetty et al. (2014a) obtain a lower estimate of 0.34 using IRS data from 1996 to 2012. Mazumder (2016), however, has argued Chetty et al.'s (2014a) lower estimates can be roughly replicated with the PSID if one imposes the same age restrictions and lengths of time averages.

None of these aforementioned studies has included a birth cohort born before 1952 and most have used birth cohorts who entered the labor market after 1980. The main contribution of our paper is providing direct evidence from uniform data for both the 1948 to 1953 cohorts and the 1961 to 1964 cohorts.

Our main finding of a sharp decline in intergenerational mobility for cohorts born in the early 1960s compared to those born around 1950 is broadly consistent with the existing literature if we consider the cohorts included in each analysis. Aaronson and Mazumder (2008) provide a useful framework for considering our results and those of the existing literature. Figure 5 plots a replication of their 
estimates of the intergenerational elasticity using Census data from 1940 to 201029 Their estimates use a group-based estimation strategy where the average income of groups of individuals defined by state and year of birth is linked to the average income of a synthetic group of parents in a prior Census who had children in the same state and year 30 The estimates in Aaronson and Mazumder are plotted by the year of income of the child and not by their birth year ${ }^{31}$ They document an increase in intergenerational mobility after 1940 and a decline after 1980 that closely tracks changes in the return to college as estimated by Goldin and Katz (1999).

The empirical results on income mobility from Chetty et al. (2014a) show that the rank-rank slope stayed roughly constant over the 2001 to 2012 period using cohorts born from 1971 to 1982 and observed at age 30. These results are easily reconciled with our findings as these individuals would have entered the labor market starting in the late 1980s at the earliest and in the late 1990s on average. This is well after the period in which we find a decline in relative intergenerational mobility. Our replication of Aaronson and Mazumder (2008) also shows relative stability in intergenerational mobility between 2000 and 2010 (Figure 5). Furthermore, if we replicate Goldin and Katz's estimates of the return to college we similarly find relative stability from 2000 to $2 0 1 0 \longdiv { 3 2 }$ Together, this all suggests our estimates are consistent with the available estimates on trends based on administrative tax records.

Seemingly at odds with our findings are the results of Hertz (2007) and Lee and Solon (2009) who show relative stability in IGE trends using the PSID. However,

\footnotetext{
${ }^{29}$ While we follow Aaronson and Mazumder (2008) and label the results by the year of the Census, the estimates are based on income measured in the year prior to the Census.

${ }^{30}$ One advantage of our analysis is that we do not need to resort to an indirect method, like Aaronson and Mazumder's synthetic cohort approach. Aaronson and Mazumder (2008) show that compared to the traditional IGE, their approach will give more weight to state-level geographic effects which could bias estimates of trends if these effects change over time. In a supplemental analysis they show that their results are robust to using state fixed effects and so they argue that trends in geographic effects are not driving their results.

${ }^{31}$ Their preferred estimates utilize controls for birth cohort bins, a quadratic in age (minus 40) and Census year effects. Their estimates can be interpreted as the IGE for a 40-year-old in a given year accounting for birth cohort and year effects. Aaronson and Mazumder also produce a set of results that ignores year effects and ascribes all changes in the intergenerational elasticity to cohorts defined in 5-year bins. In that exercise the increase in the intergenerational elasticity across birth cohorts is largest for cohorts born between 1946-50 and 1961-65, which is virtually identical to what we find in the current manuscript where we compare cohorts born between 1948-53 and 1961-64. See their figure $3 B$.

${ }^{32}$ Autor (2014) similarly finds relative stability in the returns to college over the same period using annual CPS data.
} 
there are at least two important data limitations to these and other studies using the PSID. First, in order to avoid using children living at home at later ages, these studies limit their analysis to cohorts born beginning in 1952 33 As we show in Figure 3 this misses some of the key cohorts born between 1948 and 1951 for which intergenerational persistence was rising steeply. Therefore, use of the PSID would lead to attenuated estimates of the increase in intergenerational persistence. Second, the PSID's sample sizes for each birth year cohort are only a small fraction of the corresponding sample sizes in the NLS. For example, Lee and Solon's (2009) PSID sample includes about 60 parent-son and parent-daughter pairs on average in each birth year between 1952 and 1963. By comparison, we have 251 parent-son pairs and 242 parent-daughter pairs per birth year in the NLS66 (1948 to 1953) and 524 parent-son pairs and 460 parent-daughter pairs per birth year in the NLSY79 (1961 to 1964). So our NLS cohort-based samples are 4 to 8 times larger than Lee and Solon's (2009) sample.

Hertz (2007) also uses the PSID's low-income oversample, the Survey of Economic Opportunity (SEO), so his sample sizes include around 300 children each year in the early 1950s and about 240 children each year in the early 1960s. Importantly, Lee and Solon (2009) note serious issues with the SEO. Given the issues with the SEO documented by Lee and Solon (2009), we focus our discussion of PSID based results on Lee and Solon's (2009) results.

Instead of reporting cohort-specific estimates as we do, Lee and Solon (2009) report estimates by calendar year from 1977 to 2000 using an unbalanced panel of cohorts (1952 to 1975) and each cohort is only included in the years in which they are at least 25 years old. For example, the 1952 cohort is included in all of the 1977 to 2000 estimates. The 1953 cohort is included in the 1978 to 2000 estimates. And so on. They then rely on a covariate adjustment in a regression framework to normalize the results so that their estimates can be interpreted as pertaining to a 40-year old in each calendar year.

We think that a close examination of Lee and Solon's (2009) results suggests that their results for women are actually somewhat consistent with ours. For parentdaughter pairs, the estimated IGE increases fairly gradually from 1977 to 1984. The estimate for 1977 based on 25 year olds in the 1952 cohort, which relies heavily on

\footnotetext{
${ }^{33}$ Since the PSID began in 1968, using children born in 1948 for example, would require selecting on 20 year olds who were still living at home with their parents which would be unrepresentative of the cohort.
} 
a parametric adjustment to be interpretable as the IGE for 40 year olds, is only 0.05 (0.17). The estimate for 1984, which pools the 1952 to 1959 cohorts, is 0.49 (0.10). This increase among parent-daughter pairs is suggestive of a large increase in the IGE comparable to what we find with the NLS (see Table 2). However, the large standard errors when only the oldest cohorts are included in the estimates for the late 1970s makes it difficult to distinguish an increase in intergenerational persistence from noise. For parent-son pairs, Lee and Solon report a point estimate of 0.34 with a standard error of 0.20 for the calendar year 1977 34 For their 1978 estimate, which now includes the 1953 birth cohort, the estimate rises sharply to 0.54 with a standard error of 0.13 . Thereafter, the year-by-year estimates are quite flat from 1978 onwards.

We use vastly larger samples with an explicit cohort-based sampling frame that includes cohorts who would have entered the labor market both well before and well after the inflection point in inequality in 1980. Because we have larger samples and use a cohort-based approach, we are able to directly estimate trends in intergenerational mobility rather than relying on parametric life-cycle corrections to obtain cohort-specific estimates.

Finally, there are a number of newer papers using the PSID (Hartley et al. 2017, Justman and Krush, 2013; Justman et al., 2017, Justman and Stiassnie, 2020) that have all documented sharp increases in the IGE over time making it less clear that Hertz (2007) and Lee and Solon (2009) should be viewed as the final word on cross-cohort changes in intergenerational mobility when using the PSID ${ }^{35}$

\section{Possible Mechanisms}

\subsection{Education and the Returns to Schooling}

Economic models of intergenerational mobility often highlight the fundamental role of parental investment in children's human capital as a source of intergenerational income persistence (e.g. Becker and Tomes, 1979 and 1986, Solon, 2004). There are at least two ways in which trends related to education may have resulted in an increase in persistence and a decline in mobility across the cohorts we observe. One

\footnotetext{
${ }^{34}$ By way of comparison, the standard error for the 1952 birth cohort in our analysis is 0.05 .

${ }^{35}$ For example, Figure 5 in Hartley et al. (2017) shows that the IGE in log family income for daughters rose from around 0.25 in 1980 to around 0.55 by the early $2000 \mathrm{~s}$ which is very similar to the magnitude of the both levels and change in the IGE that we find with the NLS. Recall, that we find that the IGE grew from 0.21 to 0.50 .
} 
is if children's education levels have become more strongly associated with parent income. A second possibility is if the labor market returns to education have risen. For example, Solon (2004) builds upon the Becker-Tomes model and argues that, all else equal, a rise in returns to schooling should lead to greater intergenerational persistence.

We examine these explanations in Table 7 In column 1, we find that the association between parent rank and children's years of completed education remained basically constant between the two cohort groups, increasing from 0.024 to 0.025 $(\mathrm{p}=0.81)$. In contrast, we find a large increase in the association between log parent income and children's years of education, from 0.84 to 1.06 . This difference is statistically significant at conventional levels $(\mathrm{p}=0.03){ }^{36}$

This increase in the association between parent income and education coincided with a similarly large increase in the returns to education. As shown in Figure 5. Goldin and Katz (1999) find that the returns to college increased by nearly 50 percent for prime-aged white men between the 1980 and 1990 census.

We can directly measure the returns to education in the NLS66 and NLSY79 samples by regressing log family income in the child generation on years of education interacted with an indicator for being in each survey and indicators for gender and survey. Column 3 shows the estimates from this regression. We find a large and statistically significant increase in the returns to education from 11 percent per year of education for the earlier cohorts (1948 to 1953) to 18 percent per year for the later cohorts (1961 to 1964). This two-thirds increase in the returns to education is statistically significant $(\mathrm{p}<0.01)$. Because we are using family income, this return is interpretable as a total effect of education, including, for example, the impact of education on marital partner and their income.

We assess how much of the increase in persistence is due to the increase in the returns to education using a more non-parametric measure of the returns to education. We calculate average family income separately by survey, gender, and years of education ( 8 or fewer through 16 or more). We estimate the returns as the difference between average income at each level and the average income for exactly 12 years of schooling. We generate a counterfactual income measure for each observation in the later cohorts by subtracting the estimated return to their

\footnotetext{
${ }^{36}$ Hendricks et al. (2018) find that the relationship between parent income and college attendance has declined over time as college attendance has become more strongly correlated with student ability. However, they show that this reversal had largely occurred by the 1960 cohort of high school graduates who were slightly older than our NLS66 cohorts.
} 
level of education in their own cohort group and adding in in the estimated return for their level of education based on that experienced by the earlier cohort group 37 Column 4 confirms that with this adjustment the returns to education are 11 percent per year of additional schooling for both cohort groups.

Columns 5 shows rank-rank slope estimates using child generation rank calculated based on family income measures imposing the earlier cohort groups' returns to education. The estimates for the 1948 to 1953 cohorts are identical to the full sample estimates reported in Table 2 since only the 1961 to 1964 cohorts' income is affected by the adjustment. The rank-rank slope for the later cohorts falls from 0.36 using the unadjusted data to 0.30 with the adjustment. This 0.06 unit difference is about half the size of the 0.12 unit increase in Table 2 but is still statistically significant at conventional levels $(p=0.02)$.

Column 6 shows analogous IGE estimates using log family income in the child generation that impose the early cohorts' returns to education. The later cohorts' IGE estimates falls from 0.50 to 0.44 with the adjustment. While 12 percent smaller than the unadjusted IGE, this estimate is still more than double the early cohorts' IGE of 0.21 and the difference is statistically significant $(\mathrm{p}<0.01)$.

Taken together, the results in Columns 5 and 6 strongly suggest that rising returns to education are an important contributor to the increase in intergenerational persistence across our cohort groups. However, the importance of the contribution depends on the measure of intergenerational persistence. We find that changes in the returns to schooling account for about 50 percent of the increase in the rankrank slope but only 21 percent of the increase in the IGE. These findings are broadly consistent with Aaronson and Mazumder (2008) and Levine and Mazumder (2007) who estimate a decline in other measures of intergenerational mobility that coincide with changes in the return to schooling.

\subsection{Marriage}

Table 1 shows spouses are present for 73 percent of children in the NLS66 and 60 percent of children in the NLSY79. This suggests marital patterns changed between the early and later cohorts. We consider two possible ways in which trends in marriage may matter. First, we consider whether the relationship between parent

\footnotetext{
${ }^{37}$ For example, this counterfactual income would be $\$ 23,326$ lower for an NLSY79 daughter with 16 years of education since the 1979 cohort's return was this much greater than the 1966 cohort's return.
} 
income and the likelihood of marriage has changed and second whether assortative mating has changed. Güell et al. (2015) find that the rise in assortative mating over the 20th century can explain some of the decline in intergenerational mobility in Spain. But Holmlund (2019) finds that a large decline in marital sorting had only a small impact on intergenerational persistence among cohorts born between 1945 and 1965 in Sweden.

We begin by considering changes in the "gradient" between parent rank and the probability of being married. This is shown in Table 8 . Column 1 shows that this gradient was virtually zero and statistically insignificant in our earlier cohorts, but became much steeper at 0.23 for our later cohorts. The latter estimate implies that a child with parents at the 75 th percentile is 11.5 percentage points (pp) more likely to be married than a child with parents at the 25th percentile. In contrast, the estimate for the earlier cohorts, 0.04 , implies a difference of only $2 \mathrm{pp}$ in the probability of being married for children with this same difference in parent ranks. The difference between these estimates is statistically significant $(\mathrm{p}<0.01)$. Panel $\mathrm{B}$ shows the results are similar if we instead look at the gradient between marriage and log family income in the parent generation.

For this exercise we consider someone married if they reported that they were married in each survey round used in constructing our income measure. However, the result that the gradient between parent income and the probability of being married was flat for our earlier cohorts and much steeper for the later cohorts is unchanged if we instead consider someone married if they reported being married in any of the survey rounds used in our income measure. Using this definition, we find that the rank-rank slope increased from 0.04 to 0.21 .

Because our main results use total family income in both the parent and child generation, this change in the gradient between parent income and marriage could be an important factor in explaining the increase in the persistence across cohorts. To address this, Table 8. Column 2 shows estimates of the rank-rank slope (Panel A) and IGE (Panel B) using only the child's own income from wages and salary (family income is still used for the parent generation). In this case, we find that the rank-rank slope nearly doubled, increasing from 0.15 to 0.29 . The IGE more than doubled, increasing from 0.15 to 0.38 . The differences between these estimates are both statistically significant $(\mathrm{p}<0.01$ in both cases).

Column 3 instead controls for the change in marriage rates by imputing spouse income for singles using the average spousal income of married individuals calcu- 
lated separately by survey, gender, and parent income decile. Using this alternative strategy, we find a smaller 0.05 unit increase in the rank-rank slope that is not statistically significant at conventional levels $(p=0.12)$. With this adjustment, the increase in the IGE is cut in half, falling from 0.30 to 0.13 , but remains statistically significant $(\mathrm{p}<0.01)$.

The results in Columns 2 and 3 suggest that the increase in the gradient between parent income and the probability of marriage explains up to half of the increase in persistence. But for the IGE, we continue to find a significant increase in persistence between cohorts born between 1948 and 1953 and those born between 1961 and 1964 using both of our strategies of controlling for the changing relationship between parent income and the probability of marriage.

The final two columns of Table 8 explore whether changes in assortative mating can explain the increase in persistence. We follow Holmlund (2019) and measure assortative mating by regressing our total family income measure, either the rank in the total family income distribution or log total family income, on the corresponding measure using only the child's own income. Column 4 shows the results using only married couples. The results suggest the correlation between family income and individual income ranks was basically constant between the early and later cohorts, increasing from 0.51 to 0.52 , a difference that is not statistically significant at conventional levels. In contrast, the correlation between family and own log income increased from 0.24 to 0.32 and this difference is significant at the 5 percent level.

Given that the gradient between parent income and the probability of marriage was flat for the early cohorts and steep for the later cohorts, the subsample of married couples from the later cohorts underrepresents individuals with lower income parents. To address this differential selection, Column 5 replicates the analysis in Column 4 using the full sample but imputing spouse's income for unmarried individuals using average spousal income of married individuals calculated separately by survey, gender, and parent income decile. Like the results using only married couples, these estimates show no change in assortative mating using ranks but a modest increase using log income.

We have shown that whether a child is married is much more strongly associated with both parent income rank and log income for the later cohorts than the early cohorts. If we impute potential spouses' income for singles with average spousal income by type of parent-child pair, survey and parent income decile, the increase in 
persistence between the two cohorts is largely attenuated. We find more mixed evidence that patterns of assortative mating changed between the two cohorts. Given Holmlund/s (2019) recent finding that a large change in assortative mating can have only a small impact on persistence, we interpret this mixed evidence as suggestive of a limited role for assortative mating in explaining the increase in persistence.

\section{Absolute Mobility}

Thus far all of our analysis has focused on measures of relative mobility. Relative mobility has been the focus of most of the academic literature which has been primarily concerned with equality of opportunity. A smaller literature has considered mobility with respect to absolute levels of income. Absolute mobility may have been less studied because one might have assumed that in a steadily growing economy most individuals would do better than their parents. However, in an era of rising inequality and slowing income growth, this need not be the case. Absolute mobility may also be a more intuitive concept to the broader public than relative mobility.

One particular measure of absolute that has received attention is the fraction of children whose real income exceeds that of their parents at a similar age (Isaacs et al., 2008; Chetty et al., 2017). In an influential paper, Chetty et al. (2017) find that absolute mobility by this measure has fallen sharply across the second half of the 20th century, a finding that appears to mirror our findings with relative mobility. Their baseline results, which measure income for parents and children around 30 and rely on an assumption that the copula relating parent and child income remained constant for cohorts born between 1940 and 1980, suggest absolute mobility fell by 18 percentage points (pp) between our earlier and later cohorts ${ }^{38}$ They also construct a set of bounds by relaxing the assumption that the copula was constant. Because we observe both parent and child income, we can test this directly without needing to make any assumptions about changes in the copula.

Table 9 shows estimates of the change in absolute mobility between the 1949 to 1953 cohorts and the 1961 to 1964 cohorts. Here, we focus on parent-daughter pairs because we are comparing levels of income so it is important that income be

\footnotetext{
${ }^{38}$ They estimate the copula using parent-child pairs with children born in 1980, 1981, and 1982. We calculate the 18pp decline by averaging their baseline estimate, which assumes the copula was constant between 1940 and 1980, across the NLS66 and NLSY79 cohorts. This exercise indicates absolute mobility declined from 76 percent for cohorts born between 1949 and 1953 to 58 percent for cohorts born between 1961 and 1964 .
} 
measured at a similar point in the lifecycle in both the parent and child generations. Note however that we continue to use total family income in both generations. Using all parent-daughter pairs in our main sample (Column 1), we find that absolute mobility declined by $12 \mathrm{pp}$ from 63 percent to 51 percent. The 95 percent confidence interval around this estimate includes declines as small as 8pp and as large as 17pp. While consistent with Chetty et al.'s (2017) general finding of a decline in absolute mobility, this estimate suggests a more modest decline in absolute mobility than their baseline estimate of 18pp.

In Appendix Figure A9 we show that our estimates are also consistent with Chetty et al.'s (2017) bounds. In constructing these bounds, they relax the assumption that the copula must remain stable. However, for the bounds exercise, they measure parent and child income around age 30 whereas our estimates are based on income reports when parents and children are in their early 40s. If instead, we compare our estimates to Chetty et al.'s (2017) sensitivity check that uses parent and child income measured around age 40 and assumes copula stability, our estimates actually suggest a larger decline. Their estimates suggest a 4.8pp decline from 67.4 percent for the 1949 to 1953 cohorts to 62.6 percent for the 1961 to 1964 cohorts, whereas our estimates based on observed parent-child pairs suggest a 12pp decline from 63 percent to 51 percent. Note, however, that their estimates show the biggest declines for the 1940 to 1945 cohorts so our results may differ primarily in the timing of the decline in absolute mobility.

If we restrict the sample to parent-daughter pairs for which no income measures are missing or zero (Column 2), the decline is somewhat larger at $14 \mathrm{pp}$, falling from 66 percent to 52 percent. Columns 3 and 4 show analogous estimates without the survey weights. In both cases, we find absolute mobility declined by $12 \mathrm{pp}$. Across all four specifications, we find large and statistically significant $(\mathrm{p}<0.01$ in each case) reductions in absolute mobility of between 12 and $14 \mathrm{pp}$.

For completeness, we show analogous estimates for parent-son pairs in the final four columns. Note however that these estimates are capturing a different type of mobility: the share of sons whose family income at around age 29 exceeded their parents' family income in their 40s. Consequently, the levels of this mobility measure are about 20pp lower. However, mirroring the parent-daughter results, we find a statistically significant decline of between 9pp and 12pp across the four specifications.

We saw in Section 5.5 that the NLS marginal income distribtuions differ slightly 
from the analogous income distributions based on CPS data. One might worry that these differences are biasing our estimates of absolute mobility. Appendix Table A4 shows how average parent and child generation family income changes if we re-weight the distributions to match the CPS's parent generation distribution, the CPS's child generation distribution, or with the average of these two adjustments. We can measure how much ths re-weighting matters, on average, by subtracting the adjusted average level of income from the unadjusted level. Average parent generation income decreases by $\$ 6,361$ (9 percent) and increases by $\$ 3,501$ (4 percent) for the NLS66 and NLSY79, respectively, if we re-weight to match the CPS's parent distributions. This suggests that the NLS66 sample is slightly positively selected on parent income and the NLSY79 is slightly negatively selected on parent income. In contrast, average child generation family income decreases by just under $\$ 9,500$ or 12 percent for both the NLS66 and NLSY79. We are hesitant to draw any strong conclusions from the difference in parent generation adjustments given the limited CPS data available for the NLS66's parent generation distributions. Nevertheless, we would note that the positive selection on parent income in the NLS66 and equal selection on child generation income across surveys would bias us toward finding a smaller decline in absolute mobility than we do. Appendix Table A5 shows analogous results if we re-weight our sample to match the Current Population Survey's Annual Social and Economic Supplement parent distributions, child distributions, or with the average of these two adjustments. Across all of the adjustments in these tables, the decline in absolute mobility among parent-daughter pairs ranges from 0.12 to 0.15 . The decline among parent-son pairs ranges from 0.11 to 0.13 .

Lastly, Appendix Table A6 shows our results are not sensitive to adjustments for extreme values. We find between a 12 and 14pp decline in absolute mobility among parent-daughter pairs regardless of whether we drop or topcode observations with parents or children whose income is in the top 5 pecent of their generation's income distribution. The decline among parent-son pairs is between 11 and 12pp.

\section{Conclusion}

We present the first study that utilizes the longitudinal parent and child income data available in the NLS surveys in order to document trends in intergenerational mobility. Our earlier cohorts, born between 1948 and 1953 entered the labor market during the 1960s and 1970s, well before the increase in inequality and the returns 
to schooling that took place around 1980. Our later cohorts, born between 1961 and 1964 in contrast, largely entered the labor market after the pronounced rise in inequality. We find a large and economically significant increase in intergenerational persistence between these groups. We find that the rank-rank slope rose from 0.24 to 0.36 and the IGE increased from 0.21 to 0.50 . These differences in persistence over time are comparable in magnitude to the vast geographic differences in persistence documented by Chetty et al. (2014b) for the United States. Importantly, we find no evidence that these cross-cohort changes are driven by changes in survey design, response rates, attrition, missing values or any other data anomalies.

We also find suggestive evidence that the increase in the returns to education and the sharp increase in the gradient between parent income and probability of being married are important drivers of the increase in intergenerational persistence. Nevertheless, we believe that further research is needed to more definitively understand the mechanisms behind the decline in intergenerational mobility which we document here.

We also document that absolute mobility, the share of children whose family income exceeds that of their parents, declined by $12 \mathrm{pp}$ from 63 percent to 51 percent when parent and child income is measured around age 40. These results are complementary to Chetty et al. (2017) who show that absolute mobility fell from about 90\% for children born in 1940 to 50\% for children born in the 1980s when parent and child income is measured around age 30. Since they do not observe panel data on parent and child income for cohorts born before 1980, they indirectly estimate these results by assuming the copula between the marginal distributions of parent and child income is stable for cohorts born before 1980. They further produce bounds on these estimates by relaxing the assumption that the copula stayed constant.

Since we observe both parent and child income for two sets of cohorts, we are able to directly measure the cross-cohort change in absolute mobility. Our results are consistent with the Chetty et al. (2017) bounds, but suggest a more modest decline of about $12 \mathrm{pp}$ than their baseline estimate of $18 \mathrm{pp}$. If instead we compare our estimates to Chetty et al. s (2017) sensitivity check that uses parent and child income measured around age 40 and assumes copula stability, our estimates actually suggest a larger decline. Their estimates suggest a 4.8pp decline from 67.4 percent for the 1949 to 1953 cohorts to 62.6 percent for the 1961 to 1964 cohorts, whereas our estimates based on observed parent-child pairs suggest a 12pp decline from 63 percent to 51 percent. 


\section{References}

Aaronson, D. and Mazumder, B. (2008). Intergenerational Economic Mobility in the United States, 1940 to 2000. The Journal of Human Resources, 43(1):139-172.

Autor, D. (2014). Skills, education, and the rise of earnings inequality among the 'other 99 percent'. Science, 6186:843-851.

Becker, G. and Tomes, N. (1979). An equilibrium theory of the distribution of income and intergenerational mobility. Journal of Political Economy, 87(6):1153-1189.

Becker, G. S. and Tomes, N. (1986). Human capital and the rise and fall of families. Journal of Labor Economics, 4(3):S1-S39.

Black, S. E. and Devereux, P. J. (2007). Recent developments in intergenerational mobility. In Card, D. and Ashenfelter, O., editors, Handbook of Labor Economics, 4B. North Holland.

Bloome, D. and Western, B. (2011). Cohort change and racial differences in educational and income mobility. Social Forces, 90(2):375-395.

Bratberg, E., Davis, J. M., Mazumder, B., Nybom, M., Schnitzlein, D. D., and Vaage, K. (2017). A Comparison of Intergenerational Mobility Curves in Germany, Norway, Sweden, and the US. Scandinavian Journal of Economics, 119:72-101.

Center for Human Resource Research (2001). NLSY79 User's Guide: A Guide to the 1979-2000 National Longitudinal Survey of Youth Data. Technical report, Ohio State University.

Chetty, R., Grusky, D., Hell, M., Hendren, N., Manduca, R., and Narang, J. (2017). The fading American dream: Trends in absolute mobility since 1940. Science, 356(6336):3980-3406.

Chetty, R., Hendren, N., Kline, P., and Saez, E. (2014a). Is The United States Still a Land of Opportunity: Recent Trends in Intergenerational Mobility. American Economic Review: Papers and Proceedings, 104(5):141-147.

Chetty, R., Hendren, N., Kline, P., and Saez, E. (2014b). Where is the Land of Opportunity: The Geography of Intergenerational Mobility in the United States. Quarterly Journal of Economics, 129(4):1553-1623.

Corak, M. (2013). Income inequality, equality of opportunity, and intergenerational mobility. Journal of Economic Perspectives, 27:79-102.

Dahl, M. and DeLeire, T. (2008). The association between children's earnings and father's lifetime earnings: Estimates using administrative data. Institute for Research on Poverty Discussion Paper, 1342-08. 
Goldin, C. and Katz, L. F. (1999). The Returns to Skill in the United States Across the Twentieth Century. NBER Working Paper, 7126.

Güell, M., Rodríguez, J. V., and Telmer, C. I. (2015). The informational content of surnames, the evolution of intergenerational mobility, and assortative mating. The Review of Economic Studies, 82(2):693-735.

Haider, S. and Solon, G. (2006). Life-cycle variation in the association between current and lifetime earnings. American Economic Review, 96(4):1308-1320.

Hartley, R. P., Lamarche, C., and Ziliak, J. P. (2017). Welfare reform and the intergenerational transmission of dependence. UKCPR Discussion Paper, (201601).

Hendricks, L., Herrington, C., and Schoellman, T. (2018). College access and attendance patterns: A long-run view. Working paper.

Hertz, T. (2007). Trends in Intergenerational Elasticity of Family Income in the United States. Industrial Relations, 46:22-50.

Hilger, N. G. (2017). The Great Escape: Intergenerational Mobility in the United States, 1930-2010. Working paper.

Holmlund, H. (2019). How much does marital sorting contribute to intergenerational socio-economic persistence? Journal of Human Resources (Forthcoming).

Isaacs, J. A., Sawhill, I. V., and Haskins, R. (2008). Getting Ahead or Losing Ground: Economic Mobility in America. The Brookings Institution.

Jäntti, M., Bratsberg, B., Røed, K., Raaum, O., Naylor, R., Österbacka, E., Björklund, A., and Eriksson, T. (2006). American Exceptionalism in a New Light: A Comparison of Intergenerational Earnings Mobility in the Nordic Countries, the United Kingdom and the United States. IZA DP, 1938.

Justman, M. and Krush, A. (2013). Less Equal and Less Mobile: Evidence of a Decline in Intergenerational Income Mobility in the United States. Melbourne Institute of Applied Economic and Social Research, University of Melbourne Working Paper.

Justman, M., Krush, A., and Millo, H. (2017). The intergenerational elasticity of income in the United States is rising in tandem with income inequality and returns to schools. Working paper.

Justman, M. and Stiassnie, H. (2020). Intergenerational mobility in lifetime income. Working paper.

Lee, C.-I. and Solon, G. (2009). Trends in intergenerational income mobility. The Review of Economics and Statistics, 91(4):766-772. 
Levine, D. and Mazumder, B. (2002). Choosing the right parents: Changes in the intergenerational transmission of inequality - between 1980 and the early 1990s. Federal Reserve Bank of Chicago 2002-08.

Levine, D. and Mazumder, B. (2007). The growing importance of family: Evidence from brothers' earnings. Industrial Relations, 46(1):7-21.

Long, J. and Ferrie, J. (2013). Intergenerational Occupational Mobility in Great Britain and the United States since 1850. American Economic Review, 103(4):1109-37.

Mazumder, B. (2005). Fortunate Sons: New Estimates of Intergenerational Mobility in the United States Using Social Security Earnings Data. The Review of Economics and Statistics, 87(2):235-255.

Mazumder, B. (2016). Estimating the Intergenerational Elasticity and Rank Association in the U.S.: Overcoming the Current Limitations of Tax Data. In Inequality: Causes and Consequences (Research in Labor Economics, Volume 43), pages 83 - 129. Emerald Group Publishing Limited.

Mazumder, B. (2018). Intergenerational Mobility in the US: What We Have Learned from the PSID. ANNALS of the American Academy of the Political and Social Science (Forthcoming).

Meyer, B. D. and Sullivan, J. X. (2013). Consumption and Income Inequality in the U.S. Since the 1960s. Working Paper.

Mitnik, P. A., Bryant, V., Weber, M., and Grusky, D. B. (2015). New estimates of intergenerational mobility using administrative data. Working Paper.

Nybom, M. and Stuhler, J. (2016). Interpreting trends in intergenerational mobility. Working Paper, Universidad Carlos III de Madrid.

Nybom, M. and Stuhler, J. (2017). Biases in standard measures of intergenerational income dependence. Journal of Human Resources, 52(3):800-825.

Olivetti, C. and Paserman, M. D. (2015). In the Name of the Son (and the Daughter): Intergenerational Mobility in the United States, 1850-1940. American Economic Review, 105(8):2695-2724.

Reardon, S. F., Bischoff, K., Owens, A., and Townsend, J. B. (2018). Has Income Segregation Really Increased? Bias and Bias Correction in Sample-Based Segregation Estimates. Demography, 55(6):2129-2160.

Schoeni, R. F. and Wiemers, E. E. (2015). The implications of selective attrition for estimates of intergenerational elasticity of family income. Journal of Economic Inequality, 13(3):351-372. 
Solon, G. (1992). Intergenerational Income Mobility in the United States. American Economic Review, 82(3):393-408.

Solon, G. (2004). A model of intergenerational mobility variation over time and place. In Corak, M., editor, Generational Income Mobility in North America and Europe. Cambridge University Press.

Solon, G., Haider, S. J., and Wooldridge, J. M. (2015). What are we weighting for? Journal of Human Resources, 50(2):301-316.

Topel, R. H. and Ward, M. P. (1992). Job mobility and the careers of young men. Quarterly Journal of Economics, 107(2):439-479.

\section{Tables and Figures}




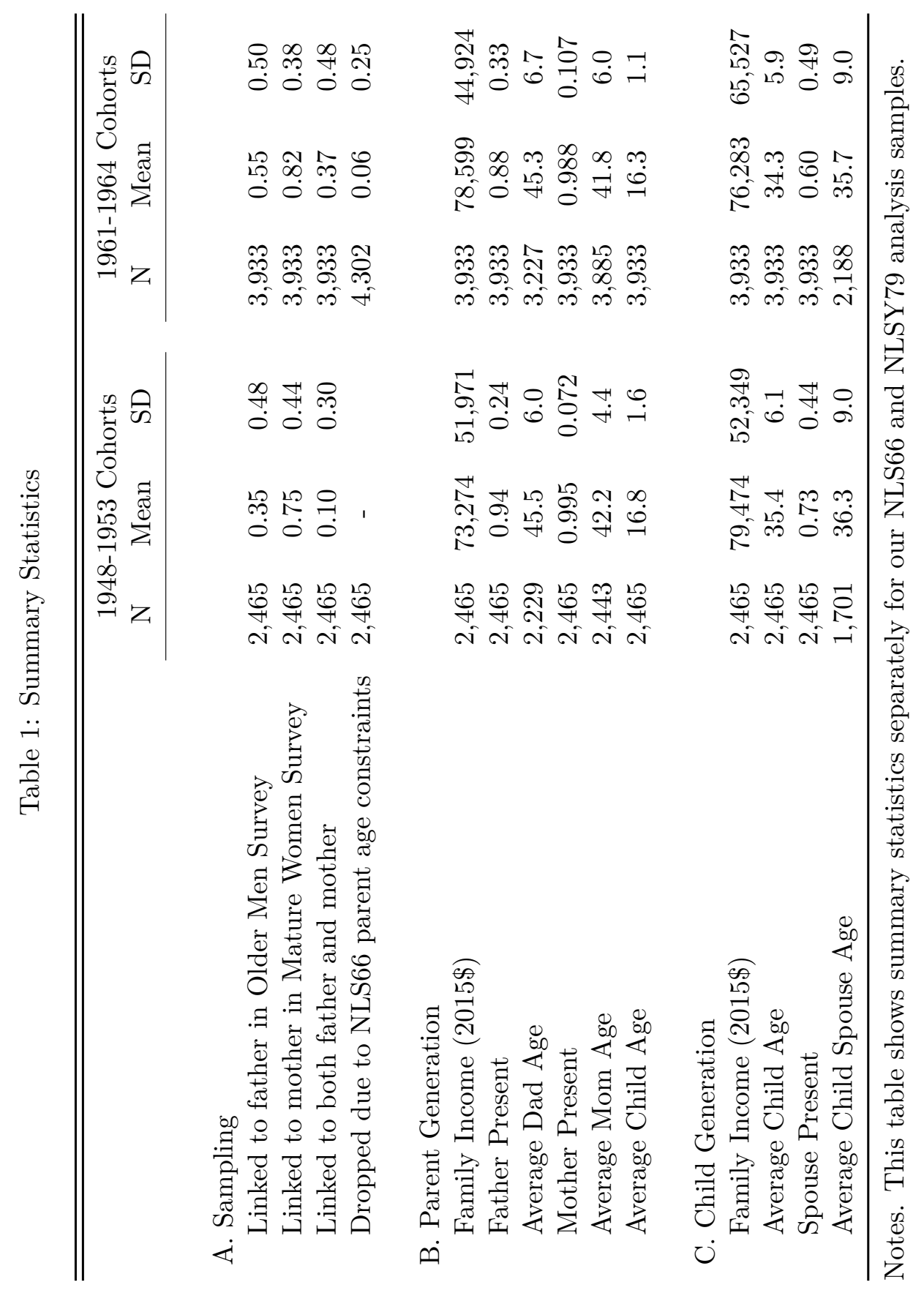




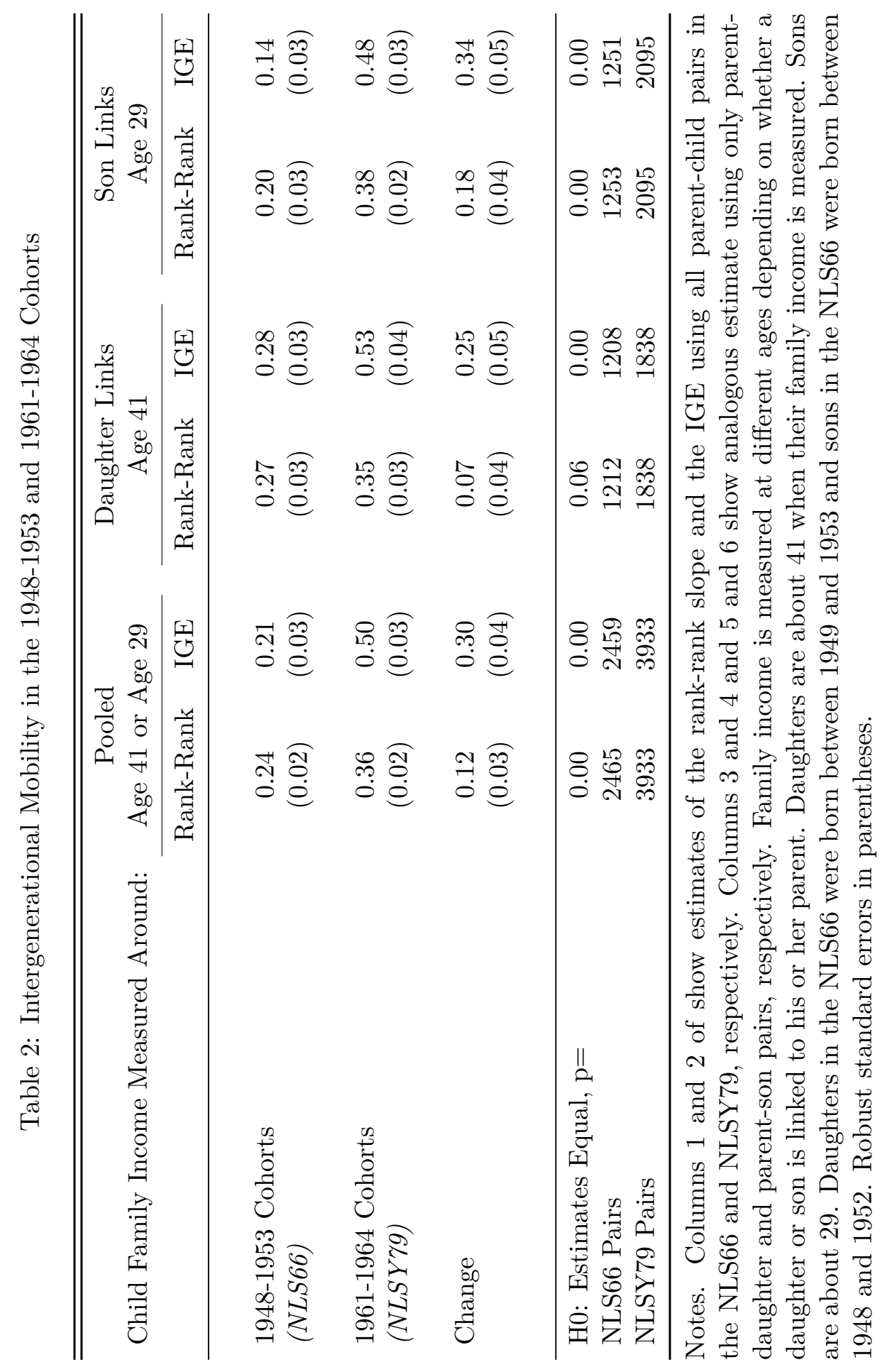


Table 3: Missingness and Zero Income in the 1948-1953 and 1961-1964 Cohorts

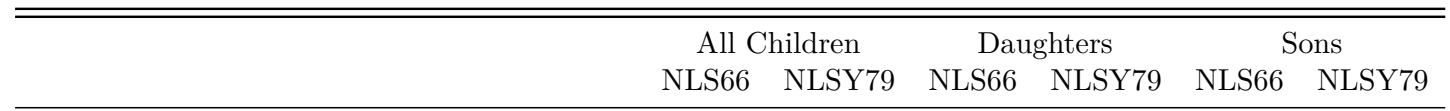

A. At least one non-zero income report

\begin{tabular}{lllllll} 
Both Generations (Main Analysis Sample) & $72.7 \%$ & $78.8 \%$ & $72.1 \%$ & $74.6 \%$ & $73.4 \%$ & $83.0 \%$ \\
Parent Generation & $99.5 \%$ & $92.3 \%$ & $99.5 \%$ & $91.8 \%$ & $99.5 \%$ & $92.8 \%$ \\
Child Generation & $72.8 \%$ & $85.4 \%$ & $72.2 \%$ & $81.1 \%$ & $73.6 \%$ & $89.5 \%$ \\
\hline
\end{tabular}

B. Parent Generation Income Summary Statistics (Main Analysis Sample)

\begin{tabular}{|c|c|c|c|c|c|c|}
\hline Non-Zero Measures & 2.89 & 2.31 & 2.90 & 2.28 & 2.88 & 2.33 \\
\hline Missing First & $0.0 \%$ & $12.4 \%$ & $0.0 \%$ & $11.9 \%$ & $0.0 \%$ & $12.9 \%$ \\
\hline Missing Second & $1.1 \%$ & $21.6 \%$ & $1.0 \%$ & $22.4 \%$ & $1.2 \%$ & $21.0 \%$ \\
\hline Missing Third & $2.1 \%$ & $34.6 \%$ & $1.2 \%$ & $37.1 \%$ & $3.2 \%$ & $32.4 \%$ \\
\hline First Zero & $2.2 \%$ & $0.1 \%$ & $2.6 \%$ & $0.1 \%$ & $1.7 \%$ & $0.1 \%$ \\
\hline Second Zero & $3.1 \%$ & $0.1 \%$ & $3.2 \%$ & $0.0 \%$ & $3.0 \%$ & $0.1 \%$ \\
\hline Third Zero & $2.4 \%$ & $0.2 \%$ & $2.4 \%$ & $0.1 \%$ & $2.4 \%$ & $0.2 \%$ \\
\hline \multicolumn{7}{|c|}{ C. Child Generation Income Summary Statistics (Main Analysis Sample) } \\
\hline Non-Zero Measures & 2.65 & 2.77 & 2.61 & 2.73 & 2.70 & 2.80 \\
\hline Missing First & $4.7 \%$ & $5.0 \%$ & $4.6 \%$ & $6.0 \%$ & $4.8 \%$ & $4.2 \%$ \\
\hline Missing Second & $8.8 \%$ & $5.3 \%$ & $9.8 \%$ & $6.7 \%$ & $7.7 \%$ & $4.1 \%$ \\
\hline Missing Third & $14.1 \%$ & $7.0 \%$ & $18.2 \%$ & $7.7 \%$ & $9.0 \%$ & $6.3 \%$ \\
\hline First Zero & $2.3 \%$ & $2.0 \%$ & $2.3 \%$ & $2.8 \%$ & $2.2 \%$ & $1.4 \%$ \\
\hline Second Zero & $3.4 \%$ & $1.5 \%$ & $3.1 \%$ & $1.7 \%$ & $3.8 \%$ & $1.2 \%$ \\
\hline Third Zero & $1.6 \%$ & $2.7 \%$ & $0.7 \%$ & $2.5 \%$ & $2.6 \%$ & $2.7 \%$ \\
\hline
\end{tabular}

Notes. Table summarizes rates of missingness and zero reports across both the NLS66 and NLSY79 in the parent and child generations. Panel A shows the rate at which we observe at least one non-zero family income measure. Panels B and $\mathrm{C}$ show details of each annual income measure included in our parent and child income measure, conditional on having at least one non-zero income measure, respectively. 
Table 4: Missingness and Zero Income in the 1948-1953 and 1961-1964 Cohorts

\begin{tabular}{lcccc}
\hline \hline & & & \multicolumn{2}{c}{ IPW Adjustment } \\
\cline { 4 - 5 } & Rank-Rank & IGE & Rank-Rank & IGE \\
\hline & 0.20 & 0.19 & 0.22 & 0.19 \\
1948-1953 Cohorts & $(0.03)$ & $(0.03)$ & $(0.03)$ & $(0.03)$ \\
$($ NLS66) & 0.33 & 0.42 & 0.36 & 0.42 \\
1961-1964 Cohorts & $(0.03)$ & $(0.03)$ & $(0.03)$ & $(0.03)$ \\
(NLSY79) & & & & \\
Change & 0.13 & 0.23 & 0.15 & 0.23 \\
& $(0.04)$ & $(0.04)$ & $(0.04)$ & $(0.04)$ \\
& & & & \\
\hline H0: Estimates Equal, $\mathrm{p}=$ & 0.00 & 0.00 & 0.00 & 0.00 \\
NLS66 Pairs & 1649 & 1649 & 1649 & 1649 \\
NLSY79 Pairs & 1542 & 1542 & 1542 & 1542 \\
\hline
\end{tabular}

Notes. Table summarizes rates of missingness and zero reports across both the NLS66 and NLSY79 in the parent and child generations. Panel A shows the rate at which we observe at least one non-zero family income measure. Panels B and $\mathrm{C}$ show details of each annual income measure included in our parent and child income measure, conditional on having at least one nonzero income measure, respectively. 
Table 5: Robustness to Extreme Values

\begin{tabular}{|c|c|c|c|c|}
\hline Adjustment & $\begin{array}{l}\text { Drop if parent } \\
\text { in top } 5 \%\end{array}$ & $\begin{array}{l}\text { Topcode if parent } \\
\quad \text { in top } 5 \%\end{array}$ & $\begin{array}{l}\text { Drop if parent or } \\
\text { child in top } 5 \%\end{array}$ & $\begin{array}{l}\text { Topcode if parent or } \\
\text { child in top } 5 \%\end{array}$ \\
\hline $\begin{array}{l}\text { A. Rank-Rank Estimates } \\
\text { 1948-1953 Cohorts } \\
\text { (NLS66) }\end{array}$ & $\begin{array}{c}0.24 \\
(0.02)\end{array}$ & $\begin{array}{c}0.24 \\
(0.02)\end{array}$ & $\begin{array}{c}0.22 \\
(0.02)\end{array}$ & $\begin{array}{c}0.24 \\
(0.02)\end{array}$ \\
\hline $\begin{array}{l}\text { 1961-1964 Cohorts } \\
\left(N L S Y^{7} 9\right)\end{array}$ & $\begin{array}{c}0.34 \\
(0.02)\end{array}$ & $\begin{array}{c}0.36 \\
(0.02)\end{array}$ & $\begin{array}{c}0.33 \\
(0.02)\end{array}$ & $\begin{array}{c}0.36 \\
(0.02)\end{array}$ \\
\hline Change & $\begin{array}{c}0.11 \\
(0.03)\end{array}$ & $\begin{array}{c}0.12 \\
(0.03)\end{array}$ & $\begin{array}{c}0.11 \\
(0.03)\end{array}$ & $\begin{array}{c}0.12 \\
(0.03)\end{array}$ \\
\hline $\begin{array}{l}\text { H0: Estimates Equal, } p= \\
\text { NLS66 Pairs } \\
\text { NLSY79 Pairs }\end{array}$ & $\begin{array}{l}0.00 \\
2363 \\
3810\end{array}$ & $\begin{array}{l}0.00 \\
2465 \\
3933\end{array}$ & $\begin{array}{l}0.00 \\
2265 \\
3689\end{array}$ & $\begin{array}{l}0.00 \\
2465 \\
3933\end{array}$ \\
\hline $\begin{array}{l}\text { B. IGE Estimates } \\
\text { 1948-1953 Cohorts } \\
(N L S 66)\end{array}$ & $\begin{array}{c}0.21 \\
(0.03)\end{array}$ & $\begin{array}{c}0.21 \\
(0.03)\end{array}$ & $\begin{array}{c}0.19 \\
(0.03)\end{array}$ & $\begin{array}{c}0.21 \\
(0.03)\end{array}$ \\
\hline $\begin{array}{l}\text { 1961-1964 Cohorts } \\
\left(N L S Y^{7} 9\right)\end{array}$ & $\begin{array}{c}0.51 \\
(0.03)\end{array}$ & $\begin{array}{c}0.50 \\
(0.03)\end{array}$ & $\begin{array}{c}0.47 \\
(0.03)\end{array}$ & $\begin{array}{c}0.51 \\
(0.03)\end{array}$ \\
\hline Change & $\begin{array}{c}0.30 \\
(0.04)\end{array}$ & $\begin{array}{c}0.30 \\
(0.04)\end{array}$ & $\begin{array}{c}0.28 \\
(0.04)\end{array}$ & $\begin{array}{c}0.30 \\
(0.04)\end{array}$ \\
\hline $\begin{array}{l}\text { H0: Estimates Equal, } p= \\
\text { NLS66 Pairs } \\
\text { NLSY79 Pairs }\end{array}$ & $\begin{array}{l}0.00 \\
2358 \\
3810\end{array}$ & $\begin{array}{l}0.00 \\
2459 \\
3933\end{array}$ & $\begin{array}{l}0.00 \\
2260 \\
3689\end{array}$ & $\begin{array}{l}0.00 \\
2459 \\
3933\end{array}$ \\
\hline
\end{tabular}

Notes. This table explores the robustness of our results to different adjustments for extreme values. Column 1 drops a parent-child pair if the parent was in the top $5 \%$ of their generation's income distribution. Rather than dropping these parent-child pairs, Column 2 topcodes parent income with the average income of parents in the top $5 \%$ of the income distribution separately by survey and whether the pair is a parent-daughter or parent-child pair. Columns 3 and 4 make analogous adjustments but for both parent and child income instead of just parent income. Panel A shows rank-rank estimates for all parent-child pairs. Panel B shows IGE estimate for all parent-child pairs. 
Table 6: Robustness to Choice of Survey Weights

\begin{tabular}{|c|c|c|c|c|c|}
\hline Weight & No Weights & First Round & $\begin{array}{l}\text { First Non-Missing in } \\
\text { Income Years }\end{array}$ & $\begin{array}{l}\text { Last Non-Missing } \\
\text { in Income Years }\end{array}$ & $\begin{array}{c}\text { Average Across } \\
\text { Income Years }\end{array}$ \\
\hline $\begin{array}{l}\text { A. Rank-Rank Estimates } \\
\text { 1948-1953 Cohorts } \\
(\text { NLS66) }\end{array}$ & $\begin{array}{c}0.30 \\
(0.02)\end{array}$ & $\begin{array}{c}0.24 \\
(0.02)\end{array}$ & $\begin{array}{c}0.25 \\
(0.02)\end{array}$ & $\begin{array}{c}0.25 \\
(0.02)\end{array}$ & $\begin{array}{c}0.25 \\
(0.02)\end{array}$ \\
\hline $\begin{array}{l}\text { 1961-1964 Cohorts } \\
\left(N L S Y^{7} 9\right)\end{array}$ & $\begin{array}{c}0.40 \\
(0.02)\end{array}$ & $\begin{array}{c}0.36 \\
(0.02)\end{array}$ & $\begin{array}{c}0.37 \\
(0.02)\end{array}$ & $\begin{array}{c}0.37 \\
(0.02)\end{array}$ & $\begin{array}{c}0.38 \\
(0.02)\end{array}$ \\
\hline Change & $\begin{array}{l}0.11 \\
0.03\end{array}$ & $\begin{array}{l}0.12 \\
0.03\end{array}$ & $\begin{array}{l}0.12 \\
0.03\end{array}$ & $\begin{array}{l}0.12 \\
0.03\end{array}$ & $\begin{array}{l}0.14 \\
0.03\end{array}$ \\
\hline $\begin{array}{l}\text { H0: Estimates Equal, } \mathrm{p}= \\
\text { NLS66 Pairs } \\
\text { NLSY79 Pairs }\end{array}$ & $\begin{array}{l}0.00 \\
2465 \\
3933\end{array}$ & $\begin{array}{l}0.00 \\
2465 \\
3933\end{array}$ & $\begin{array}{l}0.00 \\
2465 \\
3933\end{array}$ & $\begin{array}{l}0.00 \\
2465 \\
3933\end{array}$ & $\begin{array}{l}0.00 \\
2465 \\
2095\end{array}$ \\
\hline $\begin{array}{l}\text { B. IGE Estimates } \\
\text { 1948-1953 Cohorts } \\
(\text { NLS66) }\end{array}$ & $\begin{array}{c}0.24 \\
(0.02)\end{array}$ & $\begin{array}{c}0.21 \\
(0.03)\end{array}$ & $\begin{array}{c}0.21 \\
(0.03)\end{array}$ & $\begin{array}{c}0.21 \\
(0.03)\end{array}$ & $\begin{array}{c}0.21 \\
(0.03)\end{array}$ \\
\hline $\begin{array}{l}\text { 1961-1964 Cohorts } \\
\left(N L S Y^{79}\right)\end{array}$ & $\begin{array}{c}0.52 \\
(0.02)\end{array}$ & $\begin{array}{c}0.50 \\
(0.03)\end{array}$ & $\begin{array}{c}0.51 \\
(0.03)\end{array}$ & $\begin{array}{c}0.51 \\
(0.03)\end{array}$ & $\begin{array}{c}0.47 \\
(0.03)\end{array}$ \\
\hline Change & $\begin{array}{l}0.28 \\
0.03\end{array}$ & $\begin{array}{l}0.30 \\
0.04\end{array}$ & $\begin{array}{l}0.29 \\
0.04\end{array}$ & $\begin{array}{l}0.29 \\
0.04\end{array}$ & $\begin{array}{l}0.26 \\
0.04\end{array}$ \\
\hline $\begin{array}{l}\text { H0: Estimates Equal, } \mathrm{p}= \\
\text { NLS66 Pairs } \\
\text { NLSY79 Pairs }\end{array}$ & $\begin{array}{l}0.00 \\
2459 \\
3933\end{array}$ & $\begin{array}{l}0.00 \\
2459 \\
3933\end{array}$ & $\begin{array}{l}0.00 \\
2459 \\
3933\end{array}$ & $\begin{array}{l}0.00 \\
2459 \\
3933\end{array}$ & $\begin{array}{l}0.00 \\
2459 \\
2095\end{array}$ \\
\hline
\end{tabular}

Notes. This table shows our main results using different weights. The first column shows the unweighted results. The second column shows results using the weights from the first interview round, which are the weights we use in our main specification. The third and fourth columns show the results using the first or last non-missing weights during the survey rounds where we measure child income. The fifth column shows the results using the average weight across all survey rounds where we measure child income. Panel A shows rank-rank estimates for all parent-child pairs. Panel B shows IGE estimate for all parent-child pairs. 


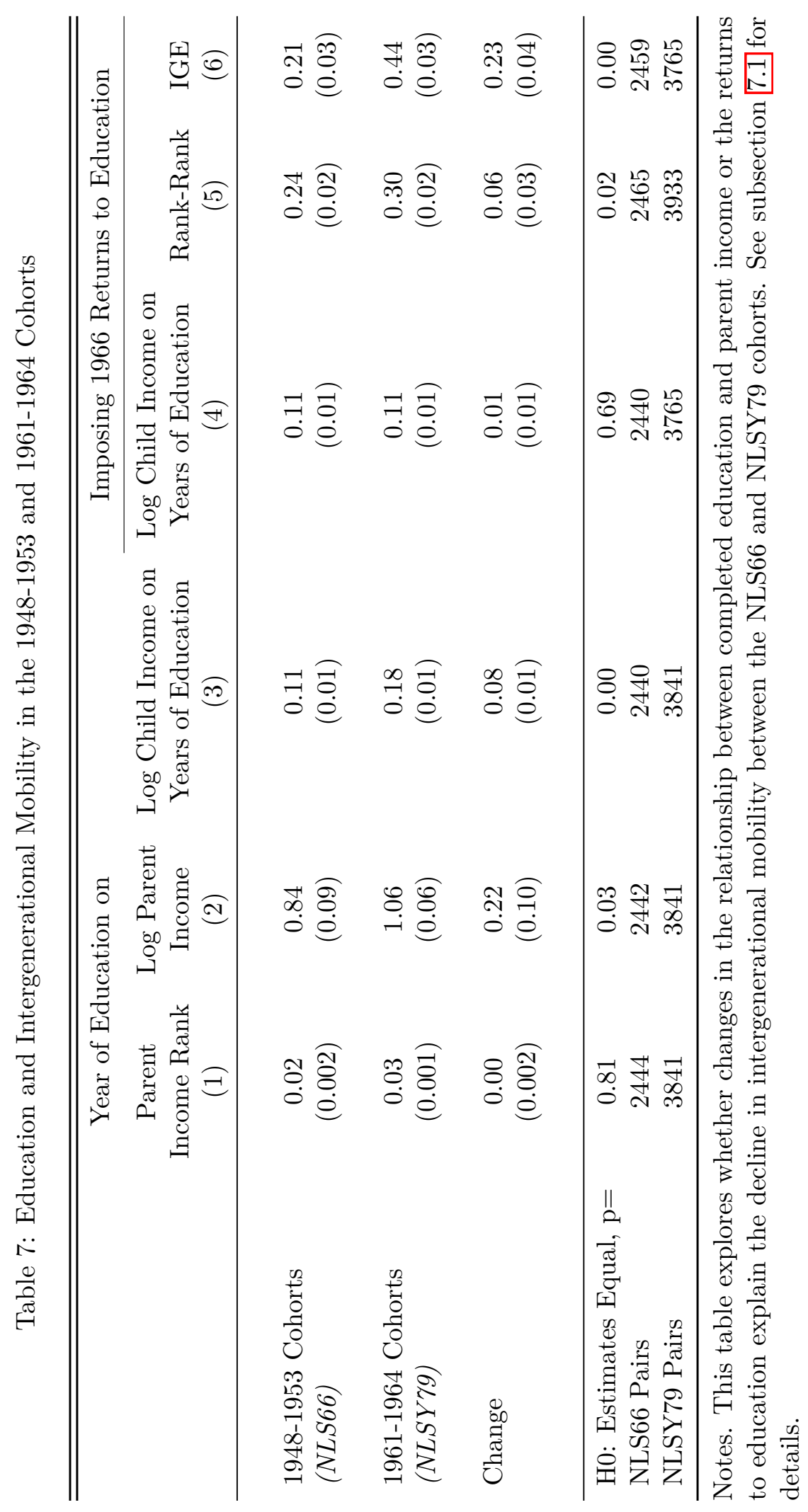




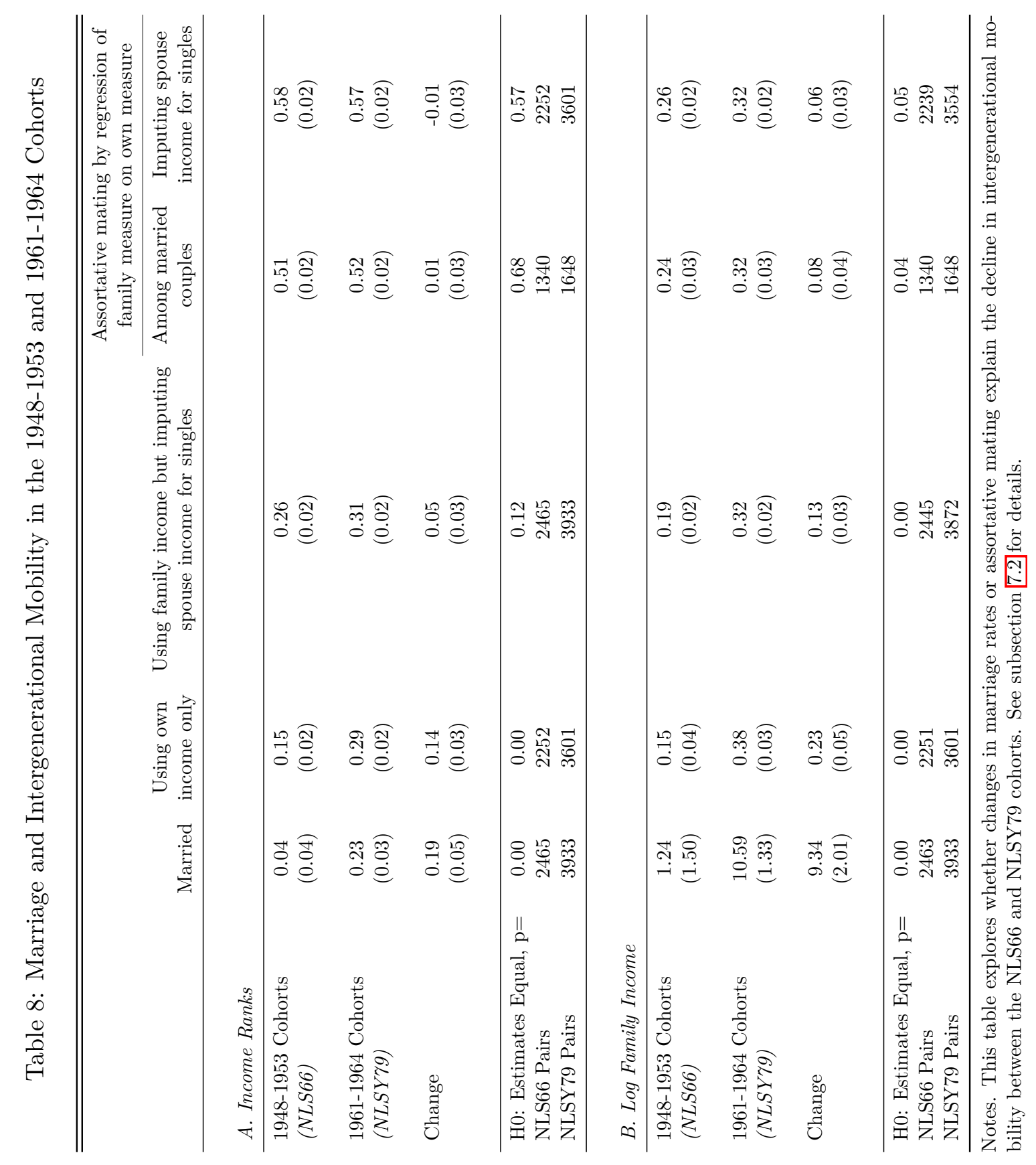




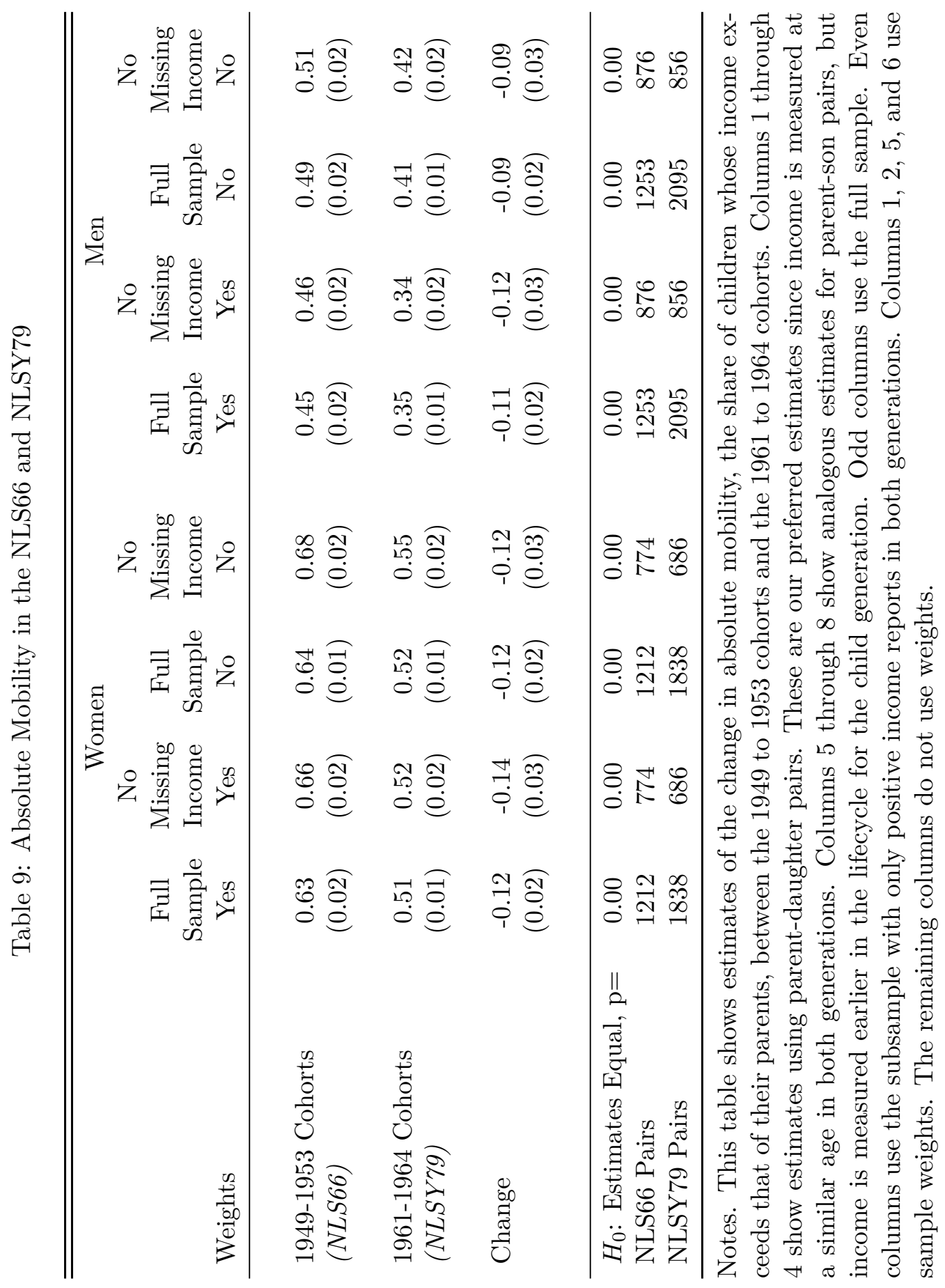


Figure 1: 90/10 Ratio and Top 1\% Income Shares, 1940-2010

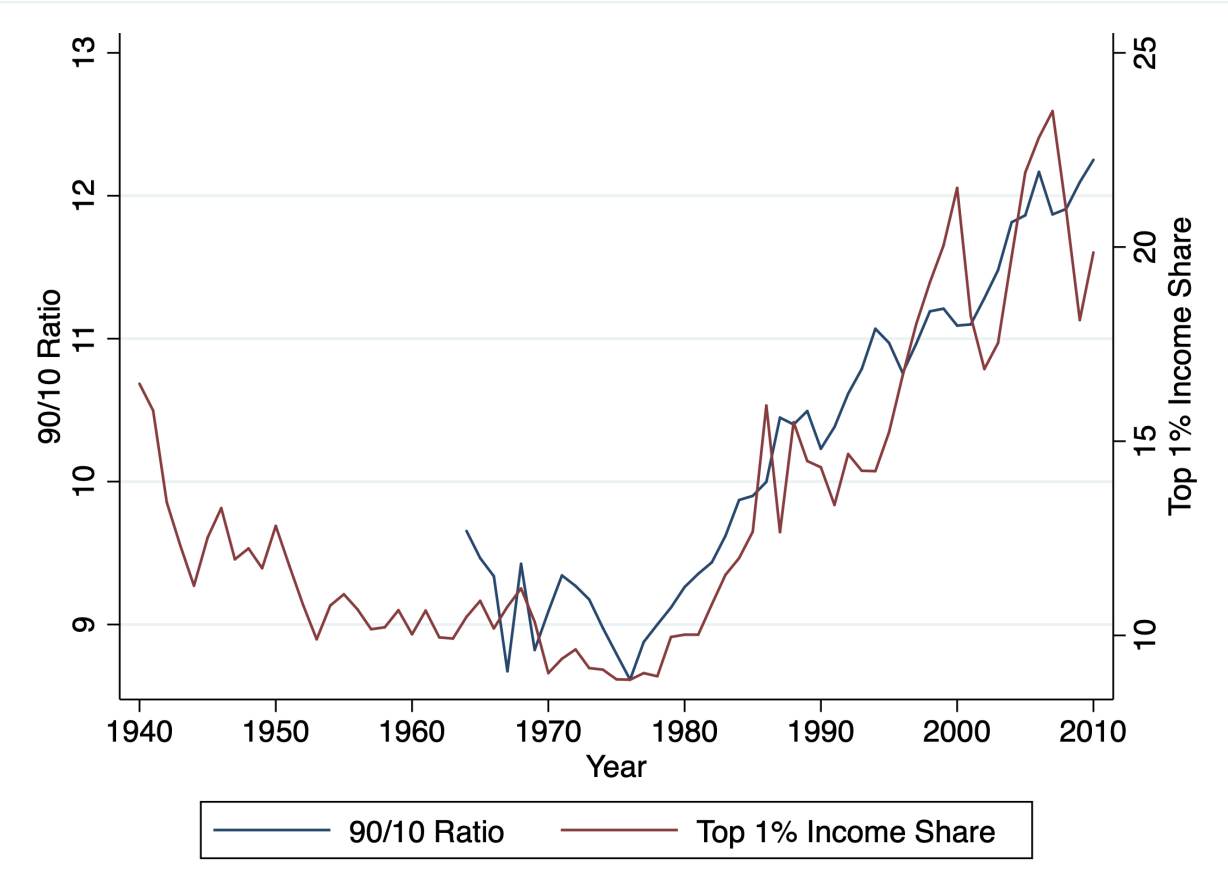

Notes. 90/10 ratio based on authors' calculations using Current Population Survey Annual Social and Economic Supplement data from 1964 to 2010. Estimate are based on average pre-tax family income among the sample of household heads weighted by the supplement weights. Top 1\% income shares based on estimates reported in Piketty and Saez (2003). The updated series was downloaded from The World Wealth and Income Database (Alvaredo et al) on December 20th, 2016. 
Figure 2: NLS66 Sampling

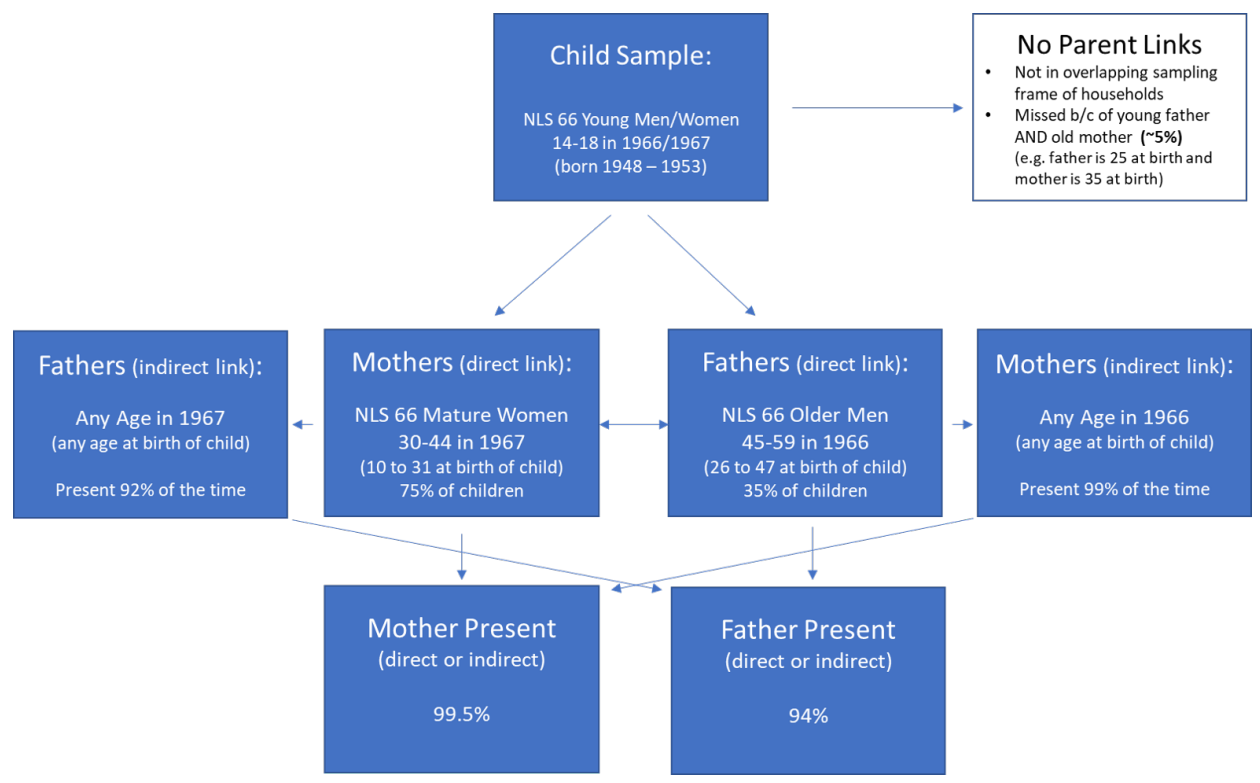

Notes. This figure summarizes the NLS66's sampling frame. To be in our sample, children needed to be linked to either a mother in the Mature Women survey or a father in the Older Men survey. In most cases, a second parent was in the household and so both parents income will be counted in our total family income measure. We estimate that we miss only about 5 to 6 percent of parent-child pairs due to this sampling restriction. We impose this same sample restriction on the NLSY79. We show that this has no effect on our NLSY79 results in Table A2 
Figure 3: Trends in Intergenerational Mobility by Birth Year
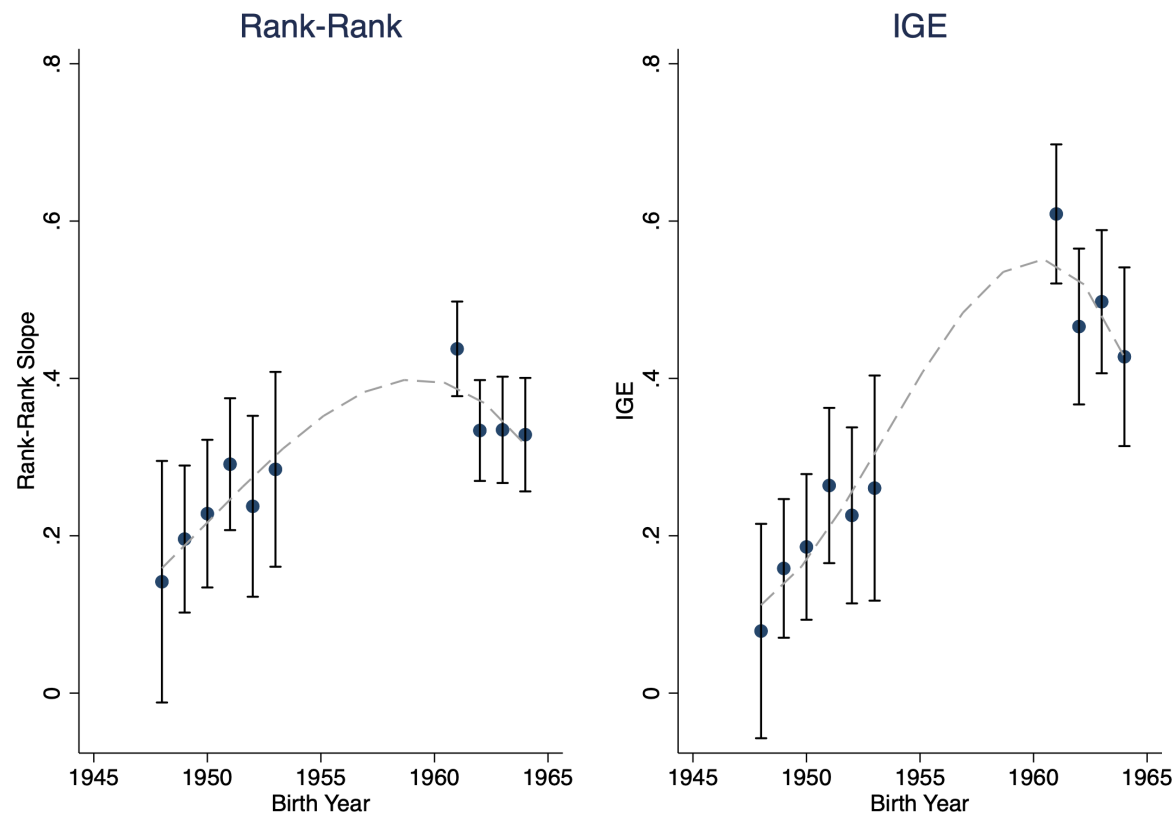

Notes. This figure shows estimates of the rank-rank slope (left panel) and IGE (right panel) for each birth year included in our main analysis. 
Figure 4: Comparison of NLS and CPS Income Distributions
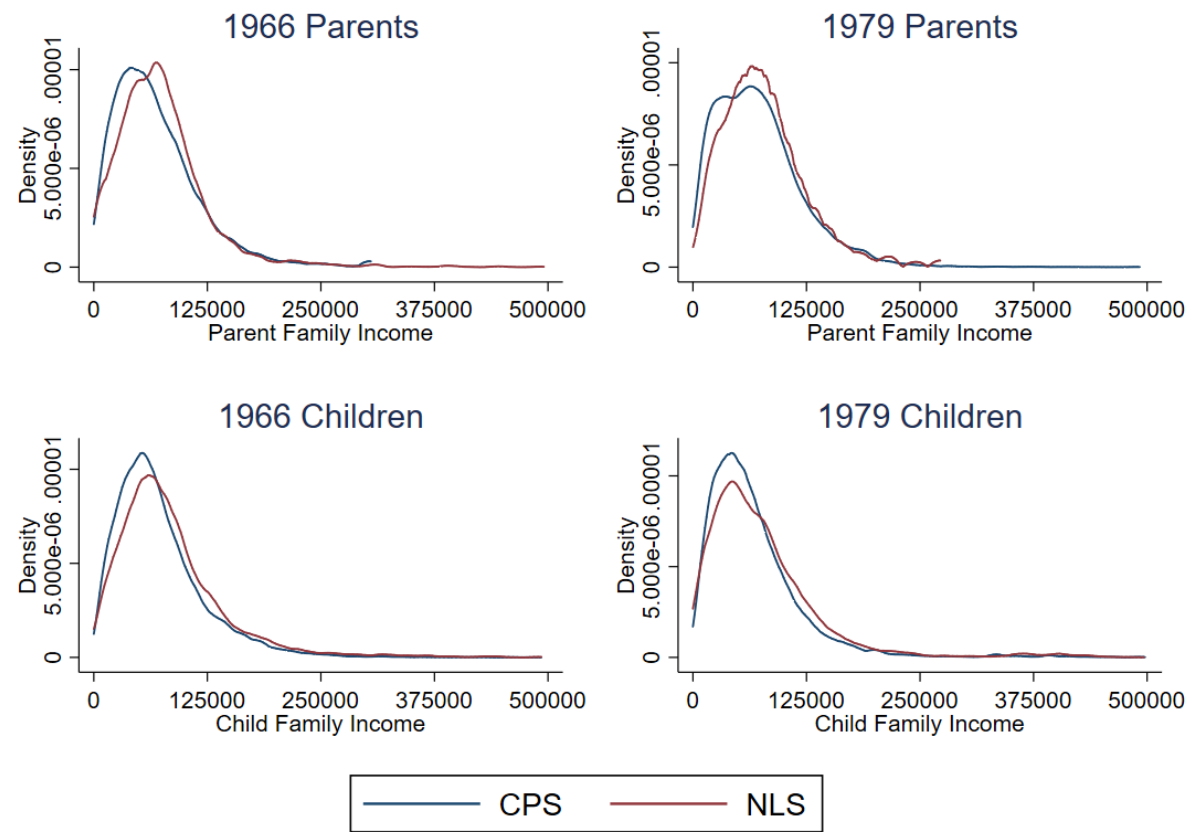

Notes. This figure plots the parent and child income distributions for the NLS66 and NLSY79 against analogous distributions from the Current Population Survey Annual Social and Economic Supplement. 
Figure 5: Trends in the IGE and Returns to College

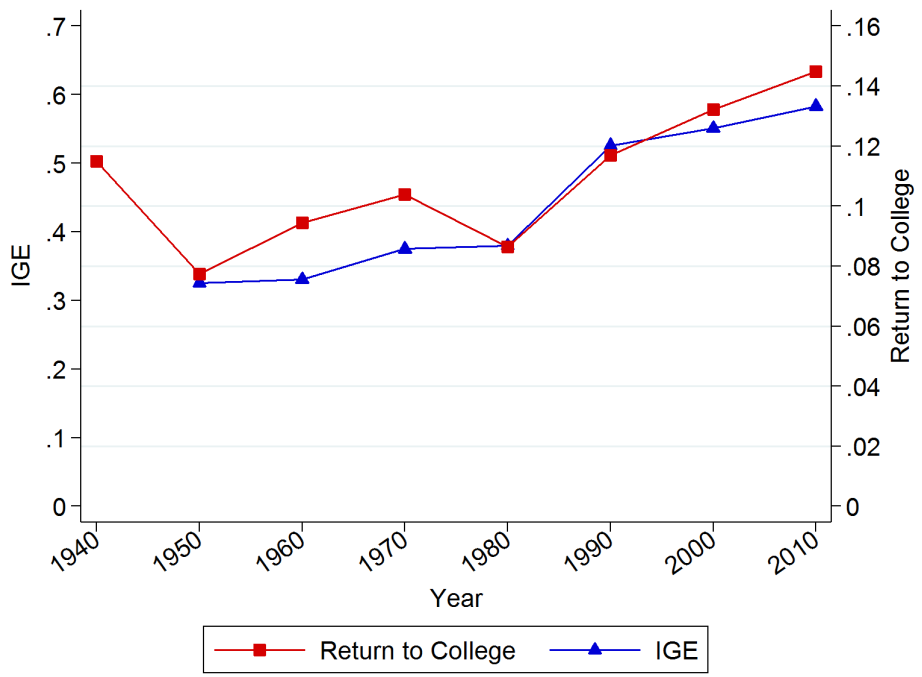

Notes. Authors' replication of Aaronson and Mazumder (2008), Figure 4.C extended to include 2010. Return to college estimated using the methodology of Goldin and Katz (2009), also extended to 2010. All calculations use decennial census and ACS data. The IGE estimates can be interpreted as the IGE for a 40-year-old in a given year accounting for birth cohort and year effects. We follow Aaronson and Mazumder (2008) and label the results by the year of the Census, the estimates are based on income measured in the year prior to the Census. 


\section{Appendix Materials}

\section{A Income Creation}

We manually create our total family income measures for all but the NLSY79 parent generation. Specifically, our total family income measure is the sum of all nonmissing income reports in that survey year. If all income reports are missing, we set total family income to missing. Otherwise, we use the reported income which implicitly assumes the missing income values were 0 . Total family income includes details about the respondent's wages from employment or self-employment, spouse's wages from employment or self-employment, income from other household members, and government transfers.

We do not manually generate total family income for the NLSY79 parent generation. In this case, parents were only asked a question about their total family income so the underlying data is not available.

We only made one modification to the underlying data. For the 1992 NLSY79 survey, which is used in the child generation family income measure for the parentson pairs, there seems to be a typo for topcoded respondent wage and salary income. In particular, the topcodes for the 1991, 1992, and 1994 surveys are $\$ 170,383$, $\$ 4,115,087$, and $\$ 167,697$ (in nominal terms). To avoid having this massive difference in topcode values drive our results, we replace the topcoded values with $\$ 167,810.28$. The average of $\$ 170,383$ and $\$ 167,697$ after converting to nominal 1991 dollars using CPI-U.

We convert our average income measures to 2015 dollars using the annual average of monthly CPI-U for all items (series ID: CUSR0000SA0). This series was downloaded from http://download.bls.gov/pub/time.series/cu/cu.data. 1.Allitems.

\section{B Appendix Tables and Figures}




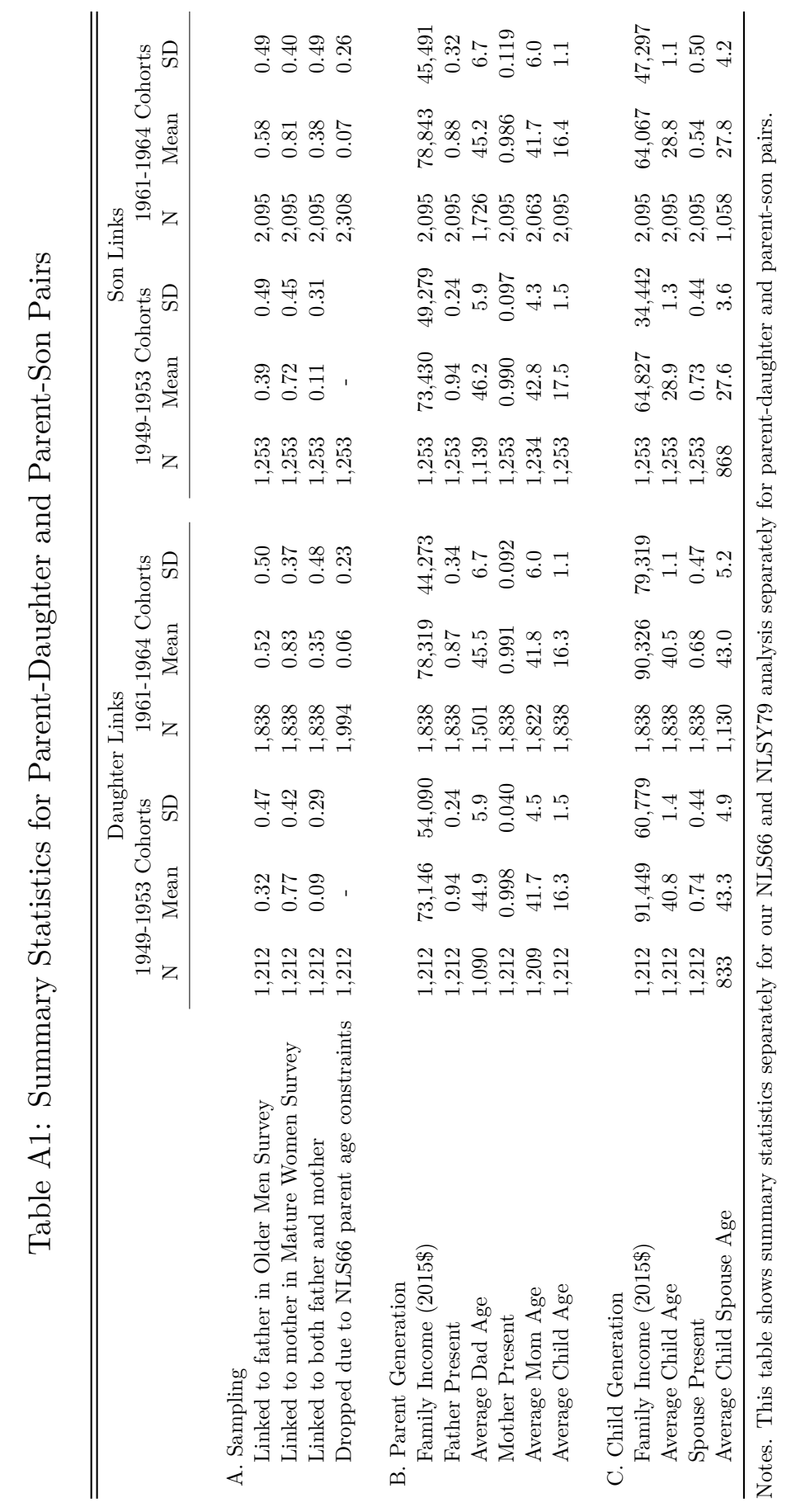




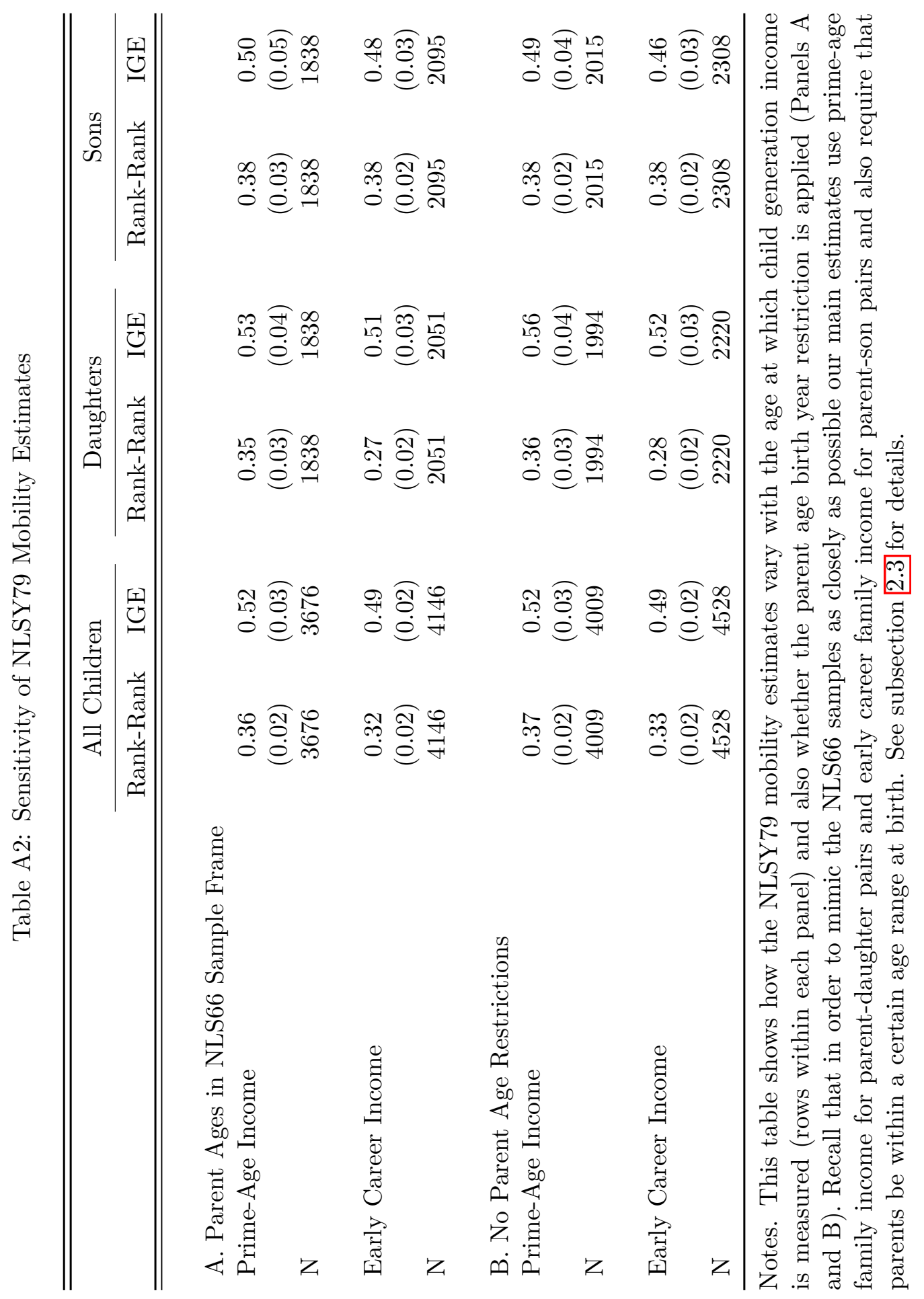




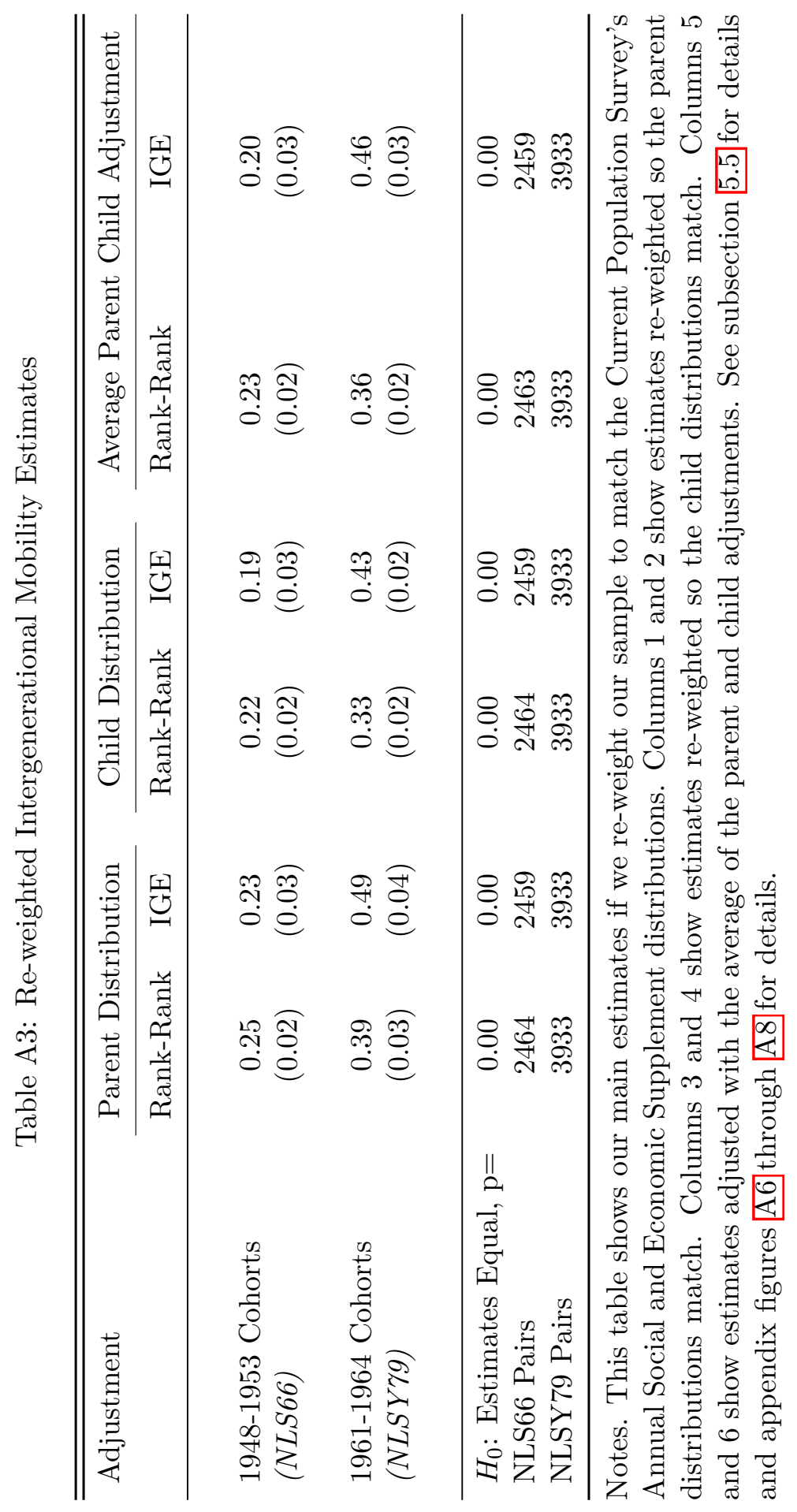




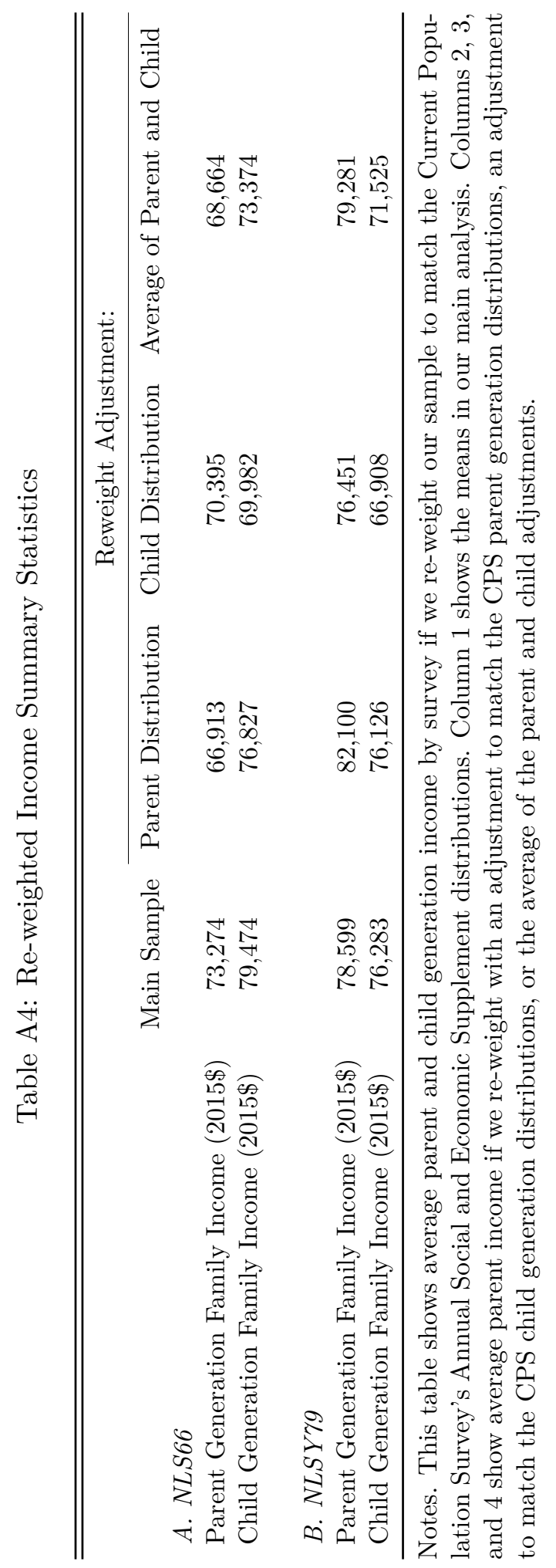




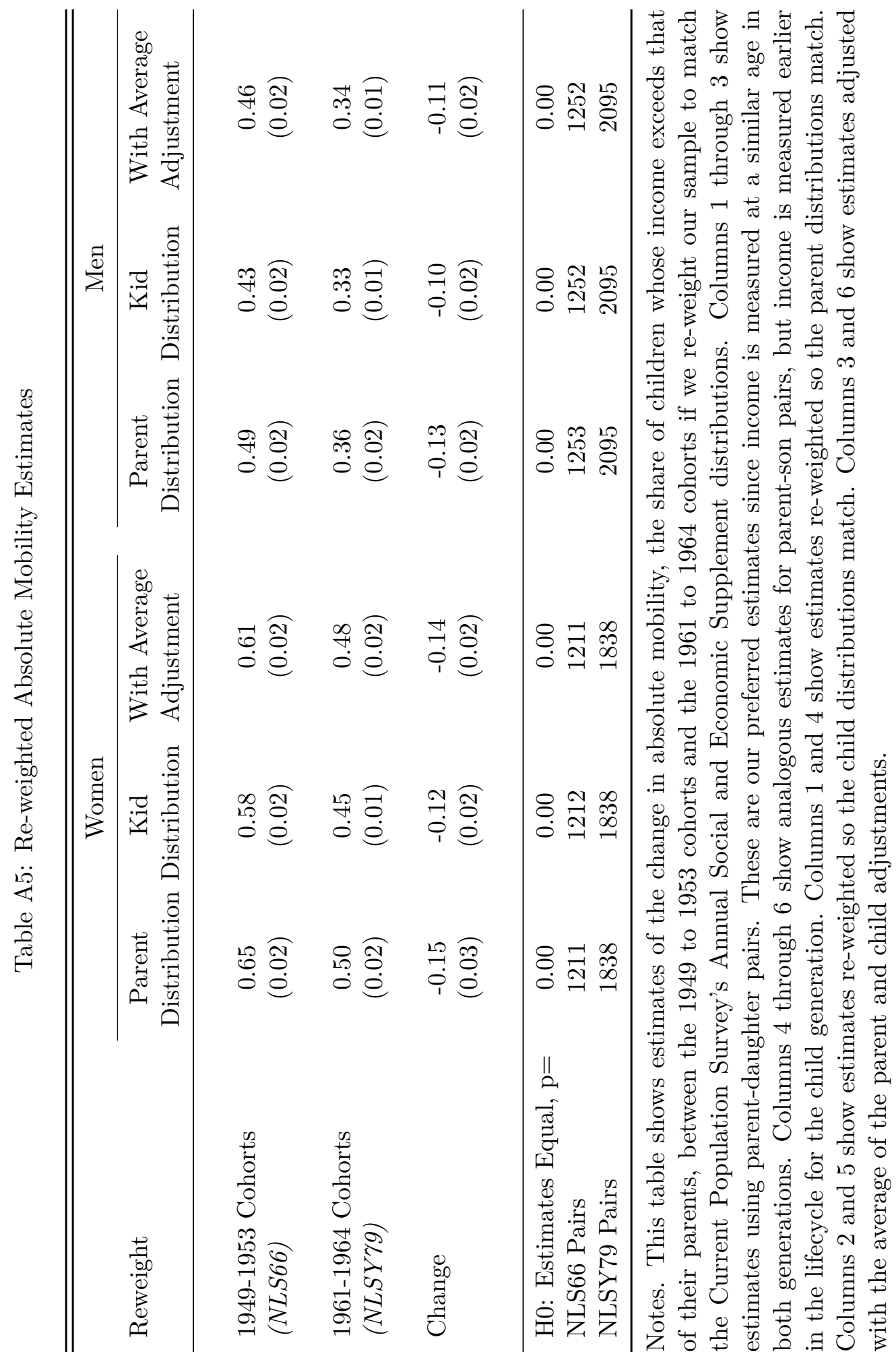




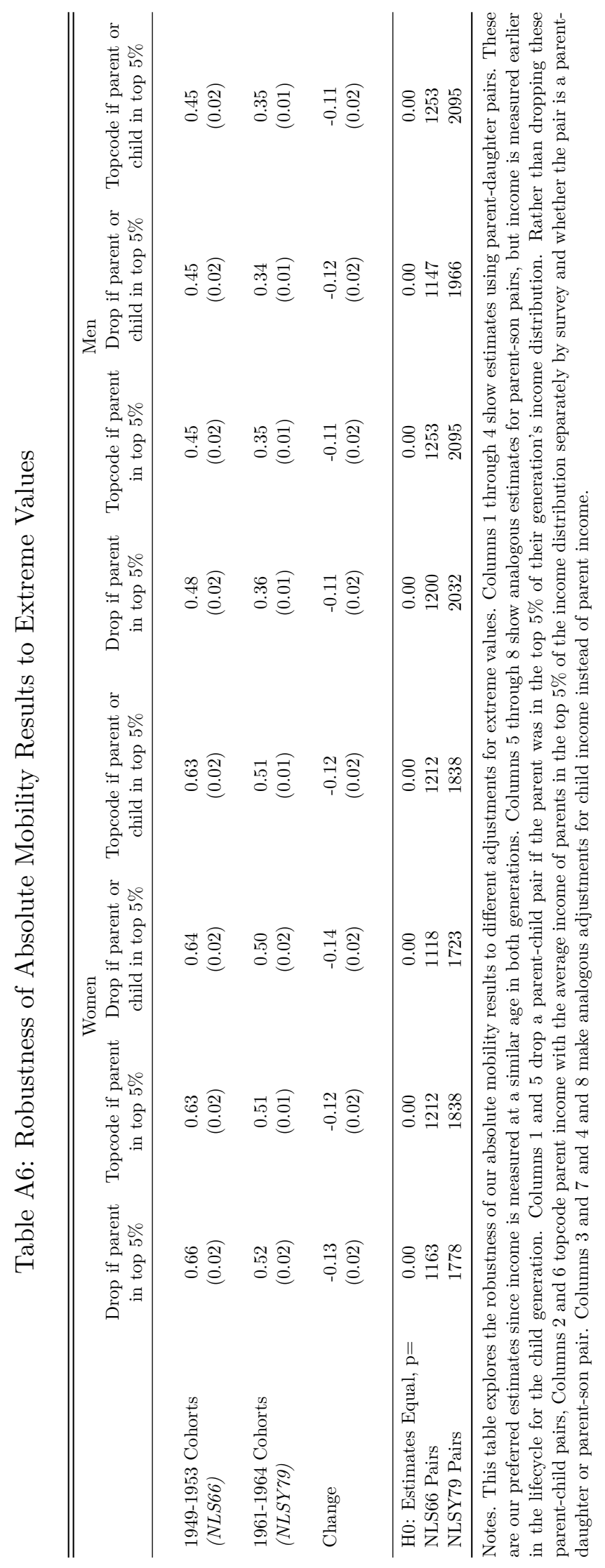


Figure A1: Robustness to Maximum Age of Child

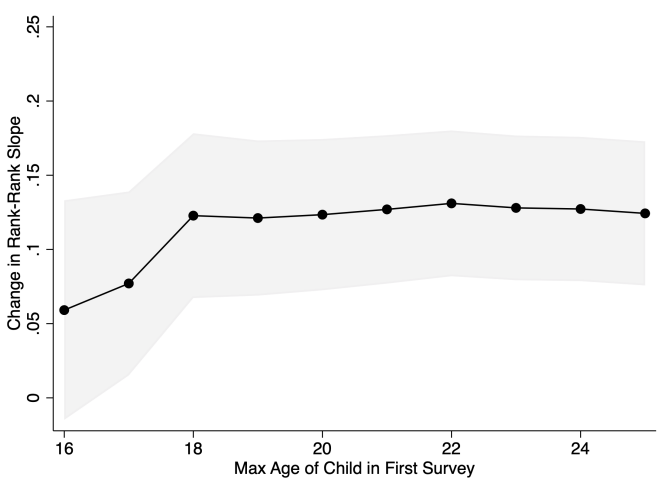

(A) Rank-Rank

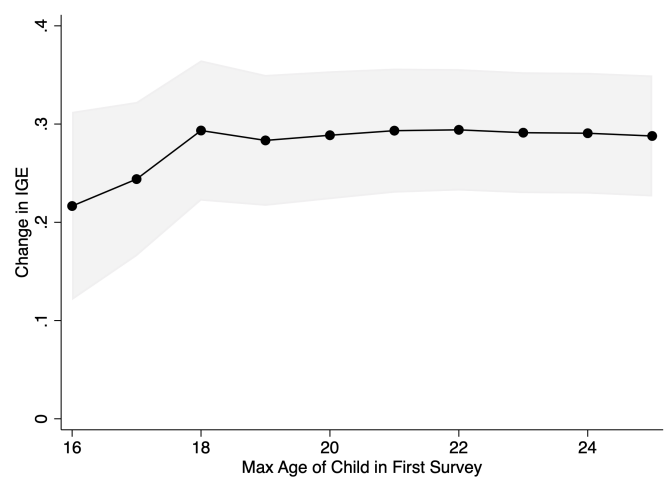

(B) IGE

Notes. In our main estimates, we restrict the sample to parent-child households where the child was 18 or younger in the first survey year. This figure shows how the rank-rank (left panel) and IGE (right panel) estimates change if we require children to have been younger or older in the first survey year. 
Figure A2: Robustness to Inclusion of Additional Controls

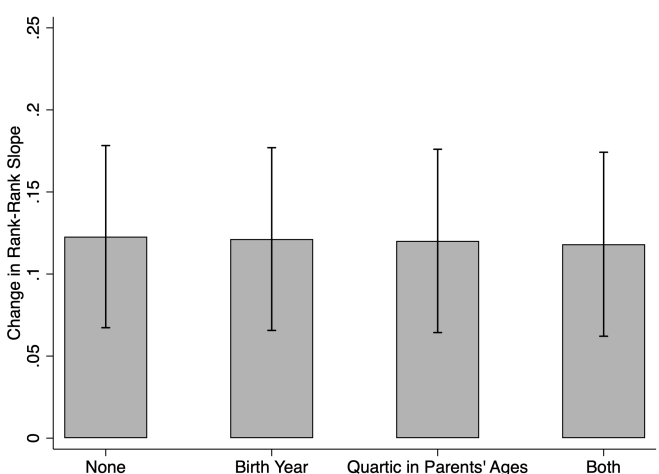

(A) Rank-Rank

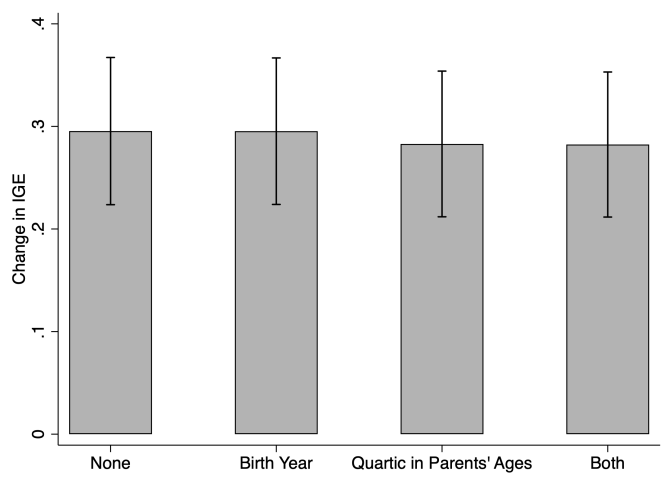

(B) IGE

Notes. This figure shows how our rank-rank (left panel) and IGE (right panel) estimates change if we add children's birth year fixed effects, a quartic polynomial in parents' age at birth, or both to our main specification. 
Figure A3: Sensitivity to Father's Age When Income Measured

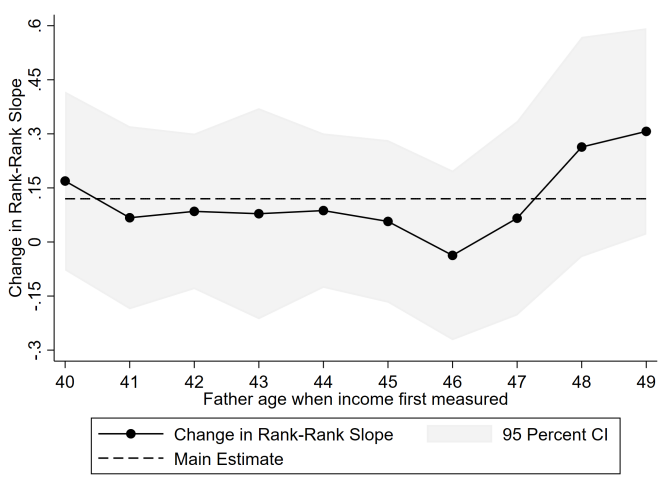

(A) Rank-Rank

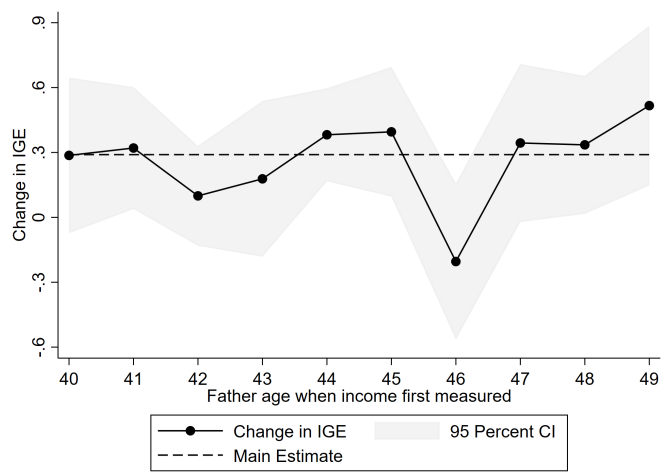

(B) IGE

Notes. This figure shows rank-rank (left panel) and IGE (right panel) estimates if we limit the sample to children whose parent generation income was measured when their father was anywhere from 40 to 49 years old in the year of the first parent generation income report. The dashed line shows the analogous estimate pooling all children from Table 2 Ranks are generated separately for each father age subsample. 
Figure A4: Binscatter Plots

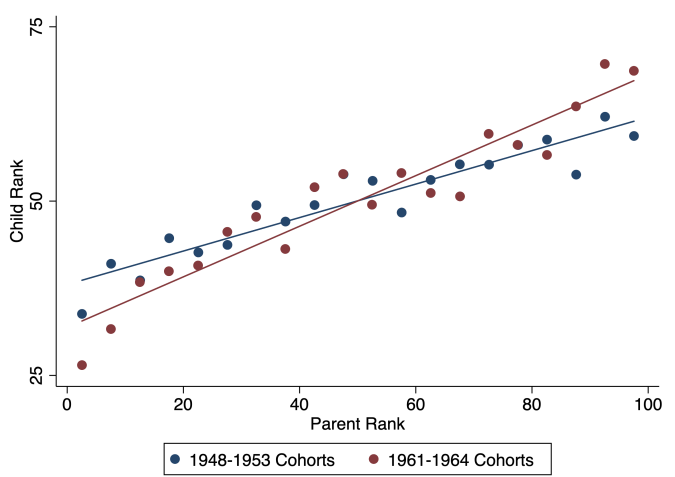

(A) Rank-Rank

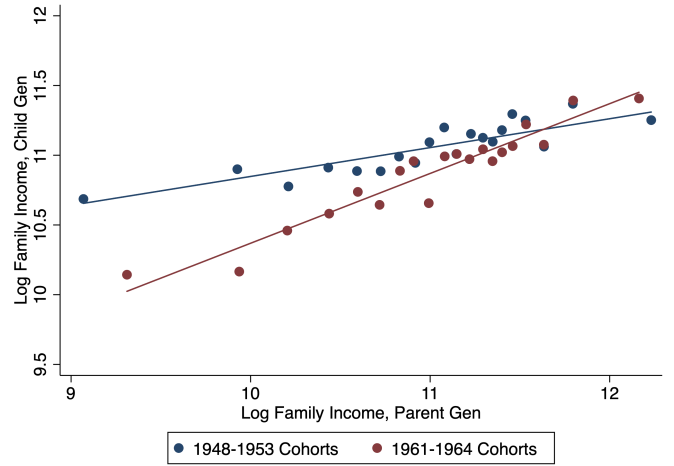

(B) IGE

Notes. This figure shows binscatter plots of child rank against parent rank and log child generation family income against log parent generation family income. These figures suggest the relationships can be appropriately modeled with linear regressions. 
Figure A5: Share of households with $<=3$ year old child with parent in age at birth window, 1940 to 1970

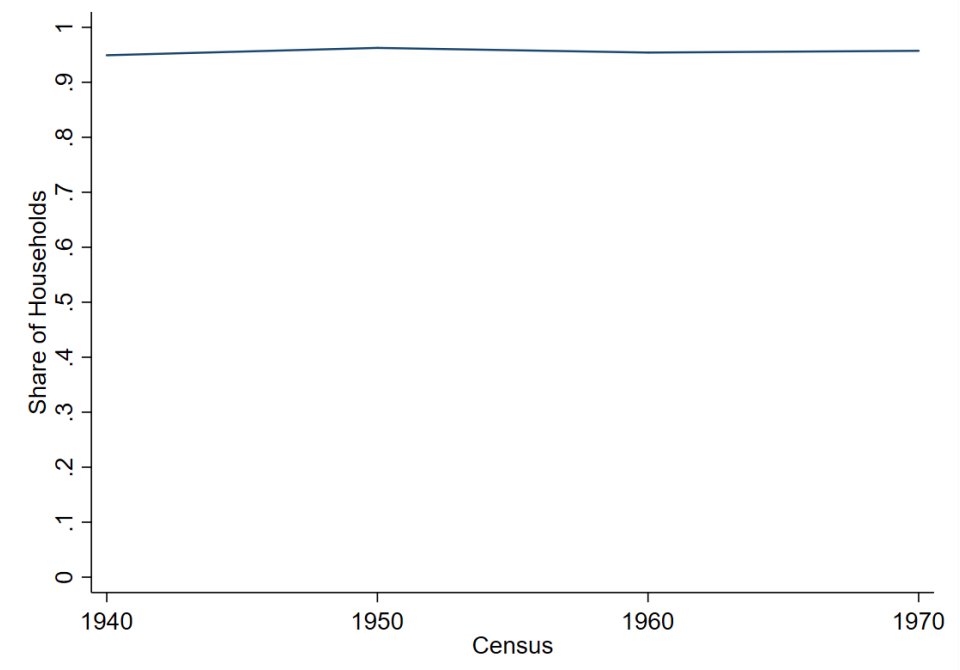

Notes. This figure shows the share of households with a child under three who has at least one parent in the age at birth ranges implied by the NLS66 sampling frame in the 1940, 1950 1960, and 1970 census. 
Figure A6: Comparison of NLS and CPS Income Distributions, Reweight Parent Distributions
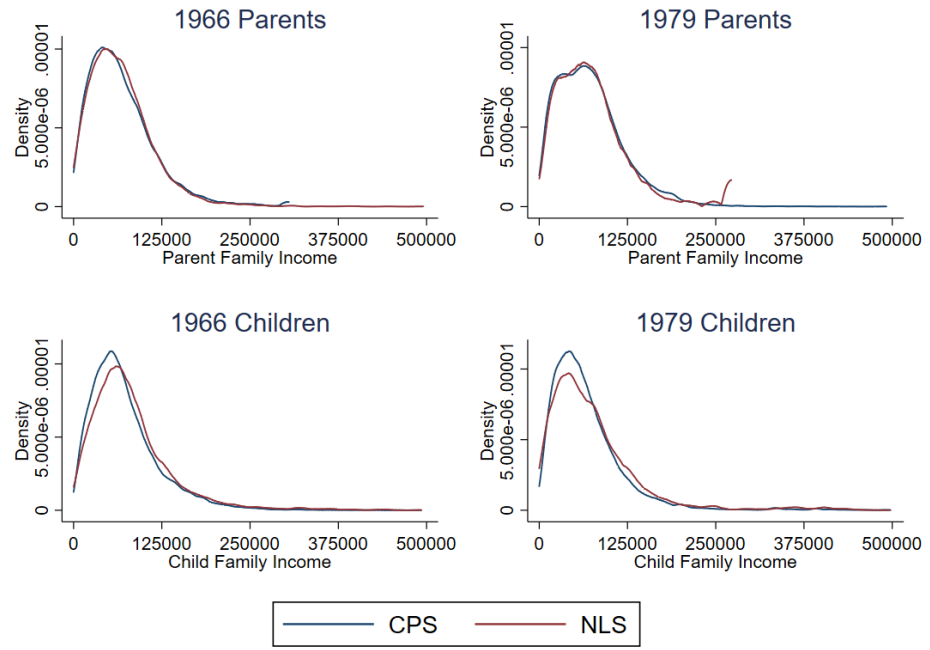

Notes. This figure plots the parent and child income distributions for the NLS66 and NLSY79 against analogous distributions from the Current Population Survey Annual Social and Economic Supplement after applying an adjustment so the NLS parent distributions match the analogous CPS distributions. 
Figure A7: Comparison of NLS and CPS Income Distributions, Reweight Child Distributions
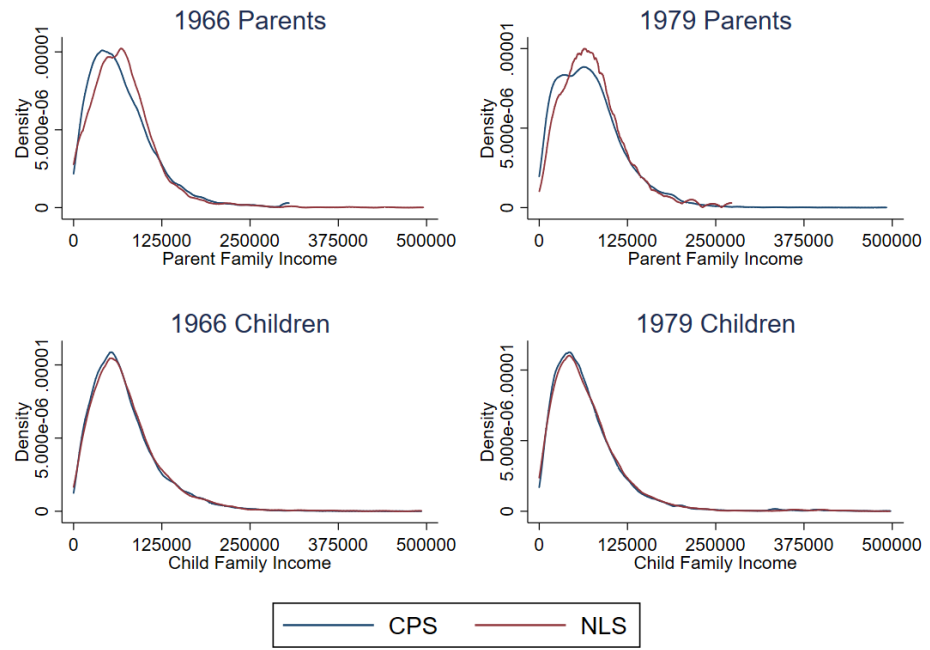

Notes. This figure plots the parent and child income distributions for the NLS66 and NLSY79 against analogous distributions from the Current Population Survey Annual Social and Economic Supplement after applying an adjustment so the NLS child distributions match the analogous CPS distributions. 
Figure A8: Comparison of NLS and CPS Income Distributions, Reweight with Average Adjustment
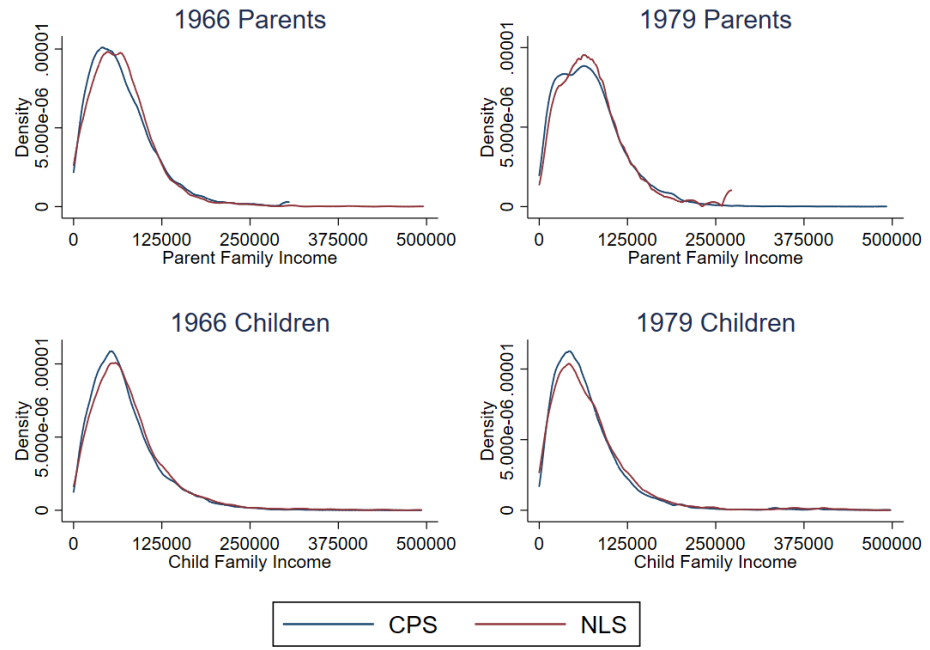

Notes. This figure plots the parent and child income distributions for the NLS66 and NLSY79 against analogous distributions from the Current Population Survey Annual Social and Economic Supplement after applying the average of the parent and child generation adjustments. 
Figure A9: Absolute Mobility, 1949 to 1953 versus 1961 to 1964

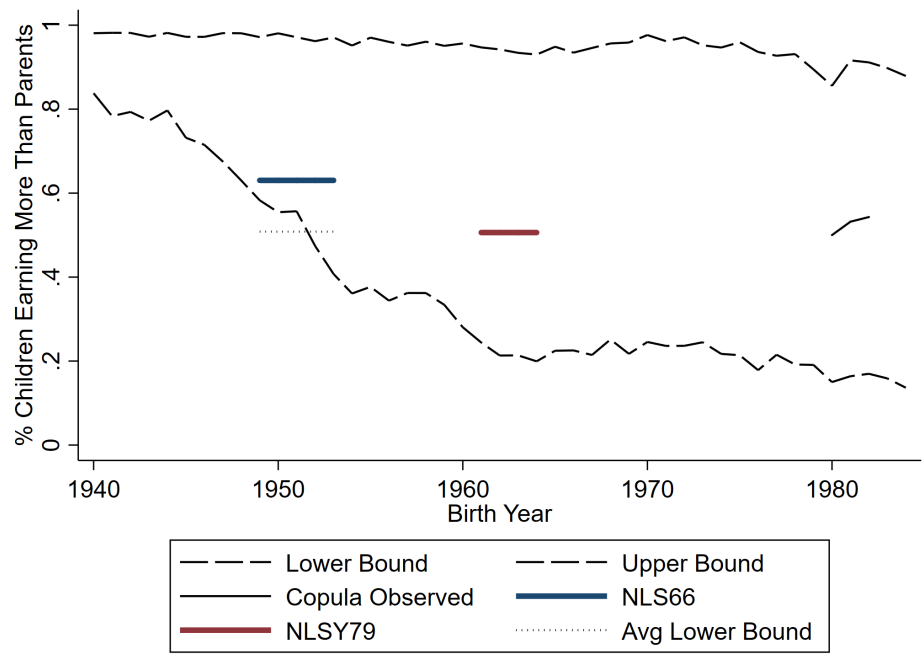

Notes. This figure combines our estimates with Chetty et al. (2017)'s bounds. The NLS66 and NLSY79 lines show the estimated rates of absolute mobility from Column 1 in Table 9] The "Avg Lower Bound" dotted line shows the average value of Chetty et al. (2017)'s lower bound between 1949 and 1953. The "copula observed" line shows Chetty et al. (2017)'s baseline estimates for 1980, 1981, and 1982, the years they observe both parent and child income. Our estimates measure parent and child income when parents and children are in their early 40s whereas their estimates measure each generation's income around age 30 . 